\title{
Large-scale differences in diversity and functional adaptations of prokaryotic communities from conserved and anthropogenically impacted mangrove sediments in a tropical estuary
}

Carolina O De Santana ${ }^{\text {Corresp., } 1}{ }^{1}$, Pieter Spealman ${ }^{2}$, Vania Melo ${ }^{3}$, David Gresham ${ }^{2}$, Taise de Jesus ${ }^{4}$, Eddy Oliveira $^{4}$, Fabio Alexandre Chinalia ${ }^{1}$

${ }^{1}$ Geosciences Institute, Federal University of Bahia, Salvador, Bahia, Brazil

2 Department of Biology, New York University, New York City, New York, United States

3 Department of Biology, Federal University of Ceará, Fortaleza, Ceará, Brazil

4 Department of Biology, State University of Feira de Santana, Feira de Santana, Bahia, Brazil

Corresponding Author: Carolina O De Santana

Email address: cal.uefsbio@yahoo.com.br

Mangroves are tropical ecosystems with strategic importance for climate change mitigation on local and global scales. They are also under considerable threat due to fragmentation, degradation, and urbanization. However, a complete understanding of how anthropogenic actions can affect microbial biodiversity and functional adaptations is still lacking. In this study, we carried out 16S rRNA gene sequencing analysis using sediment samples from two distinct mangrove areas located within the Serinhaém Estuary, Brazil. The first sampling area was located around the urban area of Ituberá, impacted by domestic sewage and urban runoff, while the second was an environmentally conserved site. Our results show significant changes in the structure of the communities between impacted and conserved sites. Biodiversity, along with functional potentials for the cycling of carbon, nitrogen, phosphorus and sulfur, were significantly increased in the urban area. We found the environmental factors of organic matter, temperature and copper were significantly correlated with the observed shifts in the communities. Contributions of specific taxa to the functional potentials were negatively correlated with biodiversity, such that fewer numbers of taxa in the conserved area contributed to the majority of the metabolic potential. The results suggest that the contamination by urban runoff may have generated a different environment that led to the extinction of some taxa observed at the conserved site. In their place we find the impacted site is enriched in prokaryotic families that are known human and animal pathogens, a clear negative effect of the urbanization process. 


\title{
1 Large-scale differences in diversity and functional
}

2 adaptations of prokaryotic communities from conserved and

3 anthropogenically impacted mangrove sediments in a

4 tropical estuary

5

6 Carolina Oliveira de Santana ${ }^{1}$; Pieter Spealman²; Vânia Maria Maciel Melo ${ }^{3}$; David Gresham²;

7 Taise Bomfim de Jesus ${ }^{4}$, Eddy José Francisco Oliveira ${ }^{4}$, Fabio Alexandre Chinalia ${ }^{1}$

8

$9 \quad{ }^{1}$ Geosciences Institute, Federal University of Bahia, Salvador, Bahia, Brazil

$10{ }^{2}$ Department of Biology, New York University, New York City, New York, United States

$11{ }^{3}$ Department of Biology, Federal University of Ceará, Fortaleza, Ceará, Brazil

$12{ }^{4}$ Department of Biology, State University of Feira de Santana, Feira de Santana, Bahia, Brazil

13

14

15

16

Corresponding Author:

Carolina Oliveira de Santana ${ }^{1}$

Av. João Durval Carneiro - 150, Feira de Santana, Bahia, 44088-714, Brazil

Email address: cal.uefsbio@yahoo.com.br

\begin{abstract}
Mangroves are tropical ecosystems with strategic importance for climate change mitigation on local and global scales. They are also under considerable threat due to fragmentation, degradation, and urbanization. However, a complete understanding of how anthropogenic actions can affect microbial biodiversity and functional adaptations is still lacking. In this study, we carried out 16S rRNA gene sequencing analysis using sediment samples from two distinct mangrove areas located within the Serinhaém Estuary, Brazil. The first sampling area was located around the urban area of Ituberá, impacted by domestic sewage and urban runoff, while the second was an environmentally conserved site. Our results show significant changes in the structure of the communities between impacted and conserved sites. Biodiversity, along with functional potentials for the cycling of carbon, nitrogen, phosphorus and sulfur, were significantly increased in the urban area. We found the environmental factors of organic matter, temperature and copper were significantly correlated with the observed shifts in the communities. Contributions of specific taxa to the functional potentials were negatively correlated with biodiversity, such that fewer numbers of taxa in the conserved area contributed to the majority of the metabolic potential. The results suggest that the contamination by urban runoff may have generated a different environment that led to the extinction of some taxa observed at the conserved site. In their place we find the impacted site is enriched in prokaryotic families that are known human and animal pathogens, a clear negative effect of the urbanization process.
\end{abstract}

Introduction 
40

41

42

43

44

45

46

47

48

49

50

51

52

53

54

55

56

57

58

59

60

61

62

63

64

65

66

67

68

69

70

71

72

73

74

75

76

77

78

79

80

81

82

83

Mangrove forests are coastal ecosystems in tropical and subtropical areas, accounting for more than $137,760 \mathrm{~km}^{2}$ of the world's coastline, with one of the largest areas being the Brazilian coast (Spalding et al. 2010; Giri et al. 2011). These ecosystems are recognized to be of strategic importance for climate change mitigation, due to their large capacity for carbon sequestration and storage, as well as for protecting the coast from erosion and rising sea levels (Howard et al. 2017; Macreadie et al. 2019). Many aspects of mangrove health and function are tied to microbial metabolic activities that play essential roles in large-scale biogeochemical nutrient cycling and as such have been the subject of many genomic studies (Yun, Deng, and Zhang 2017; Zhou et al. 2017; Imchen et al. 2017; Imchen et al. 2018; Marcos et al. 2018; Lin et al. 2019; Allard et al. 2020).

Globally, mangrove ecosystems are threatened by habitat degradation and loss due to anthropogenic disturbances such as urbanization, industrial development and increasing population densities in coastal areas (Fernandes et al. 2014; Imchen et al. 2018; Gong et al. 2019; Trevathan-Tackett et al. 2019). In Brazil, where a large number of mangrove studies have been performed, numerous studies have been conducted in disturbed mangroves (Andreote et al. 2012; Sanders et al. 2014; Cabral et al. 2016), mostly without direct comparison to undisturbed sites. Undisturbed mangrove sites have been conserved within Brazil's Permanent Protection Areas, as defined by the National Council on the Environment (CONAMA) through the resolution No. 303 of 2002 (CONAMA, 2002). Critically, this resolution was revoked in September of 2020, thus increasing the risks of degradation of such areas in the future.

One important Permanent Protection Area in Brazil, located in Bahia State, is the Pratigi area which is characterized by the presence of small urban areas interspersed within dense Atlantic Rainforest vegetation. Notably, when the Pratigi Protection Area was created in 1998, several small urban locations were already present, and were integrated in the efforts for a sustainable use of the natural resources (MMA, 2004). Despite the presence of these urban assemblages, the area has continuously received high environmental quality indices (Lopes 2011; Ditt et al. 2013; Mascarenhas et al. 2019; Carneiro et al. 2021). Nevertheless, even with this high level of environmental quality across the entire area, some local anthropogenic disturbance is still present, such as construction in what was a mangrove forest around the city of Ituberá (Fig. 1). In this location, it is possible to observe clear signs of anthropogenic impact, such as raw sewage and urban runoff, as well as the withdrawal of the native vegetation from the immediate vicinity.

The existence of a small locus of disturbance within a largely conserved estuarine system provides for an opportunity to study how human activities impact microbial populations. In this study, we aimed to assess the impacts of urbanization on the surrounding mangrove area by examining the prokaryotic communities of sediments and their potential functional roles in the context of the local disturbance around Ituberá city, in comparison to the results of a distant and conserved spot in the same estuarine system. Considering the increased risks of environmental disruption now that the protection legislation has been revoked, this study provides important elements for the understanding of the consequences of even light urbanization and minor human interference in a mangrove area.

Prokaryotes, specifically bacteria, comprise the large majority of the sediment microbiomes of mangrove ecosystems in Brazil and worldwide, accounting for 94.8 to $99.2 \%$ of the microbial diversity (Andreote et al. 2012; Imchen et al. 2018). Previous research conducted in Goa, India (Fernandes et al. 2014) and the Red Sea region (Ullah et al. 2017) found higher diversity in anthropogenically impacted mangroves in comparison to conserved areas, possibly due to the higher availability of a wide variety of organic and inorganic compounds, which favors the colonization of exogenous opportunistic prokaryotes 
84 ultimately creating significantly distinct communities. In this study, we hypothesized that proximity to

85 urban environments and sources of constant input of domestic runoff leads to large-scale changes in 86 prokaryotic composition and functional profiles in the microbiome of mangrove sediments. Considering 87 the importance of prokaryotes in such areas, we conducted 16S rRNA gene sequencing analysis in both 88 conserved and impacted mangrove areas within the Serinhaém estuary, and measured the correlations 89 between the prokaryotic communities and environmental factors for each site. Using the taxonomic 90 abundances obtained with the analysis of the 16S rRNA, we estimated the general patterns of functional 91 potentials in these microbiomes.

92

\section{Materials \& Methods}

\section{Study area}

The Serinhaém estuary (Fig. 1) is located within the limits of the Environmental Protection Area of Pratigi in the state of Bahia, Brazil. The Pratigi Protection Area is defined as an area of sustainable use aiming for the protection of remnants of the Brazilian Atlantic Forest and associated ecosystems, such as restingas and mangroves, in which extractive and agricultural activities are still allowed but regulated (MMA, 2004; Ribeiro et al. 2019). This estuarine region covers approximately $32 \mathrm{~km}$ of the Juliana River basin, a riverine system that is completely inside the limits of the protected area, and flows into Camamu Bay, a tropical oligotrophic estuarine system, where it meets the Atlantic Ocean. Ituberá is a relatively small urban area of approximately 28,000 people (IBGE 2020) within the Pratigi APA, with a strong economic focus on tourism. For the selection of collection sites we coordinated with the Organização de Conservação da Terra (OCT) which manages conservation actions within the protection area of Pratigi.

\section{Sampling}

The two collection sites were located 9.5 kilometers distant from each other. The mangrove trees at both collection sites are composed of the species Rhizophora mangle, Avicennia schaueriana and Laguncularia racemosa (MDMA, 2010). Collections were performed at the morning low tide. For both sites, cores consisting of the top $10 \mathrm{~cm}$ of the surface layer were collected using a stainless-steel cylindrical sediment core sampler with a diameter of $10 \mathrm{~cm}$, always avoiding mangrove trees and rhizosphere associated sediments (de Santana et al. 2021).

At the conserved mangrove site $\left(13^{\circ} 44^{\prime} 34.6^{\prime \prime} \mathrm{S}, 39^{\circ} 03^{\prime} 30.6^{\prime \prime} \mathrm{W}\right)$, collection points withing each tidal zone (supralittoral, intertidal and sublittoral) were $15 \mathrm{~m}$ distant from each other. Within each tidal zone we collected 3 sediment samples, each sample consisting of 3 combined sediment cores taken within an immediate vicinity $(50-60 \mathrm{~cm}$ ), resulting in 9 samples at this site (de Santana et al. 2021). Collections were made in July 2018. The conserved collection site exhibited no visible signs of anthropogenic disturbance or pollution. For this study, we recombined the FASTQ files of these 9 samples into three composite replicates, where each replicate included one sample from each tidal zone (Supplemental Text S1).

The samples from the impacted site $\left(13^{\circ} 44^{\prime} 11.1^{\prime \prime} \mathrm{S}, 39^{\circ} 08^{\prime} 46.0^{\prime \prime} \mathrm{W}\right)$ located just outside the city of Ituberá, were collected in triplicate, each sample was located $5 \mathrm{~m}$ from the other two in a triangle covering the sublittoral zone. As with the conserved samples, each impacted sample was composed of 3 sediment cores, taken within an immediate vicinity of 50-60 cm. Collections were made in February 2020. The definition of mangrove associated tidal zones in this area was complicated by the advance of the city's construction, resulting in a smaller and partially deforested area. The emerged sediments at the time of collection showed pollution by domestic runoff and construction leftovers. Because of the absence 
128

129

130

131

132

133

134

135

136

137

138

139

140

141

142

143

144

145

146

147

148

149

150

151

152

153

154

155

156

157

158

159

160

161

162

163

164

165

166

167

168

169

170

171

of waste management infrastructure, numerous developments along the shore where the sediments were taken exhibited sewage waste pipes directly releasing into the environment (Supplemental Figure S1). In both collection sites the sediments from the submerged zone present a silt/mud constitution (Santos and Nolasco 2017) and were collected within the tree line.

Sediments were transported in plastic bags inside thermic boxes filled with ice to the laboratory of Petroleum Studies in the Federal University of Bahia. Samples from both sites had plants and other macroscopic organic materials removed before subsequent procedures.

For each sediment sampling site we measured physical-chemical parameters such as dissolved oxygen, conductivity, $\mathrm{pH}$ and temperature in the water column directly above the sampling spot of submerged sediments, using a multiparameter monitoring system (YSI model 85, Columbus). For each sediment core an aliquot was separated for the measurement of organic matter content using the 'loss-onignition' method (Nelson and Sommers 1996) and the other part was kept in the $-20^{\circ} \mathrm{C}$ freezer for DNA extraction.

For heavy metal analysis we relied on previously performed work (Pereira 2016) which identified the background metal concentrations in the sediments of the entire estuarine channel. The analysis of heavy metals was carried out as described in (Pereira 2016). Briefly, $0.5 \mathrm{~g}$ of the clay fraction of the airdried samples were transferred to test tubes $(25 \times 25 \mathrm{~mm})$ added with a solution of hydrochloric acid $(\mathrm{HCl})$ and nitric acid (HNO 3) at the ratio 3:1 (3 $\mathrm{mL} \mathrm{HCl}$ and $1 \mathrm{~mL} \mathrm{HNO} 3)$ and placed in the $100{ }^{\circ} \mathrm{C}$ digester block for 24 hours along with analytical blanks. After digestion, samples were filtered and placed in 50 $\mathrm{ml}$ volumetric flasks, added with ultrapure water to the extent of $25 \mathrm{ml}$ and subsequently analyzed to determine the concentrations of the metals $\mathrm{Al}, \mathrm{As}, \mathrm{Ba}, \mathrm{Co}, \mathrm{Cr}, \mathrm{Cu}, \mathrm{Fe}, \mathrm{Li}, \mathrm{Mn}, \mathrm{Ni}, \mathrm{Pb}, \mathrm{Sn}, \mathrm{V}$, and $\mathrm{Zn}$ by Inductively Coupled Plasma - Optical Emission Spectrometry (ICP / OES) (Agilent Technologies - 700 series). Data from those downstream sites closest to the sediment sampling sites (Supplemental Text S1), had an average distance of $1.64 \mathrm{~km}$ for the impacted site and $6.98 \mathrm{~km}$ for the conserved site. KruskalWallis was performed to identify significant differences in values between the two sites (Supplemental Text S1).

\section{DNA extraction, amplicon library generation, and sequencing}

Total genomic DNA was extracted using PowerSoil DNA Isolation Kit (Qiagen, Carlsbad, CA, USA) from $0.25 \mathrm{~g}$ of each composite sample and stored at $-80^{\circ} \mathrm{C}$ before amplification, resulting in 9 DNA samples for the conserved site and 3 DNA samples for the impacted site. For amplification of the V4 region of the prokaryotic 16S rRNA gene we performed PCR using the primer pairs. For the conserved site we used 515F-Y(Parada, Needham, and Fuhrman 2016) and 806R-XT (Caporaso et al. 2011), while 515F and 806R (Kozich et al. 2013) were used for the impacted samples. Each sample required a minimum of $12.5 \mathrm{ng}$ before PCR as quantified using Qubit (Thermo Scientific, Waltham, MA USA). For PCR we used the following protocol: for $2.5 \mu 1$ of each sample (minimum $5 \mathrm{ng} / \mu \mathrm{L}$ ), $5 \mu 1$ of the forward and reverse primers and $12.5 \mu \mathrm{l}$ of the 2x KAPA HiFi HotStart ReadyMix were added, to the total volume of $25 \mu$. The samples were then subjected to following cycles: $1 \times 95^{\circ} \mathrm{C}$ for 3 minutes, $25 \mathrm{x}$ $95^{\circ} \mathrm{C}$ for 30 seconds, $1 \times 55^{\circ} \mathrm{C}$ for 30 seconds and $1 \times 72^{\circ} \mathrm{C}$ for 30 seconds and $1 \times 72^{\circ} \mathrm{C}$ for 5 minutes. Negative controls were also used in parallel and ran on an agarose gel, as no band resolved these were not sequenced. PCR cleanup was performed using Ampure XP beads. Amplicon libraries were prepared using the Nextera XT according to manufacturer's directions (Illumina, San Diego, CA, USA). Final quantification and pooling were performed using KAPA HiFi. For the conserved site we loaded $\sim 6 \mathrm{pM}$ of each sample for paired-end sequencing (2x150) (Caporaso et al. 2012) performed using the Illumina

Peer] reviewing PDF | (2021:04:60025:2:1:NEW 29 Aug 2021) 
172 MiSeq platform (Illumina, San Diego, CA, USA), V2 kit (300 cycles), while the impacted site we used

$173 \sim 48 \mathrm{pM}$ of each sample for paired-end sequencing $(2 \times 250)$ using the Illumina NovaSeq XP (Illumina, San

174 Diego, CA, USA). It is possible that these methodological differences in library preparation and

175 sequencing may produce artifactual differences in the two data sets.Data analysis

176 Read preprocessing

177

178

Demultiplexed sequences were filtered and trimmed with Trimmomatic (Bolger, Lohse, and

179 SLIDINGWINDOW:4:15 MINLEN:100) with the requirement of a minimum average read quality score

180 of 15 for inclusion. For each read, the sliding window cuts any read at the point where the median quality

181 score over a 4 nt window is less than 15.

182

183

184

185

186

187

188

189

190

191

192

193

194

195

196

197

198

199

200

201

202

203

204

205

206

207

208

209

210

211

212

213

214

215

\section{Paired-end merge, denoise, and chimera removal using DADA2}

Paired reads from the conserved site were combined as described previously (de Santana et al. 2021), briefly, paired reads were combined using QIIME2 for reads with an overlap greater than 9 while paired reads with an overlap greater than 6 were combined using a custom script (Supplemental Text S1) before denoising using DADA2 (denoise-single, --p-trim-left 3, --p-trunc-len 0, --p-max-ee 2.0, --p-truncq 2). The reads from the impacted site were also denoised using DADA2 (denoise-paired, --p-trim-left-f 13, --p-trim-left-r 13, --p-trunc-len-f 150, --p-trunc-len-r 150). These were then merged with the denoised sequences from the conserved site for further analysis. Reads were resolved and clustered into amplicon sequence variants (ASVs) using QIIME2 (Bolyen et al. 2019). All ASVs were retained in the data set. Filtering was performed only on taxa and only for differential abundance analysis.

Taxonomic assignment was performed using QIIME2's naive Bayes scikit-learn classifier (Bokulich et al. 2018) trained using the 16S rRNA gene sequences in SILVA database (Silva SSU 132), (McDonald et al. 2012), (Supplemental Text S1). Taxonomic counts were also used for hierarchical correlation clustering (Supplemental Text S1) tests using gneiss in QIIME2.

Unnormalized ASV (Supplemental Table S1) and taxonomic abundances (Supplemental Table S2) as well as overlap (Supplemental Text S1) between sites are reported in supplemental material.

\section{ASV analysis using QIIME2}

Alpha-rarefaction curves were generated using QIIME2 (Supplemental Text S1). We performed a variety of alpha-diversity (Kruskal-Wallis statistic, and Supplemental Fig. S2) and beta-diversity tests (PERMANOVA statistic, Supplemental Fig. S3). As both Kruskal-Wallis and PERMANOVA are nonparametric tests we did not test for normality. However, both are sensitive to homoscedasticity. For Kruskal-Wallis we used Levene's test $(\mathrm{Df}=1, \mathrm{~F}$-value $=0.2275$, $\mathrm{p}$-value $=0.6334)$ and betadisper (Anderson 2006) for PERMANOVA ( $\mathrm{Df}=1$, Sum_Sq $=0.002209$, Mean_Sq $=0.002209$, F-value $=0.8045$, p-value $=0.4205)$.

\section{Environmental variable correlations using Vegan}

Correlations between taxonomic community structure and environmental variables associated with the sample sites were tested using the Vegan package (version 2.5-6) (Dixon 2003) in R (R Core Team 2019). Distance matrices were calculated using vegfit (default settings) on taxa abundance identified by QIIME2 for each site. We performed constrained ordination of the distance matrices (PCoA) using envfit (default settings). 
216

217

218

219

220

221

222

223

224

225

226

227

228

229

230

231

232

233

234

235

236

237

238

239

240

241

242

243

244

245

246

247

248

249

250

251

252

253

254

255

256

257

258

259

\section{Potential functional analysis using PICRUSt2}

We used PICRUSt2 (version 2.3.0-b) (Ye and Doak 2009; Louca and Doebeli 2018; Douglas et al. 2019; Barbera et al. 2019; Czech, Barbera, and Stamatakis 2020) with default settings for functional analysis using the observed ASV abundances generated by QIIME2. It is important to note that functional predictions generated by PICRUSt 2 using 16S rRNA sequences alone will not be as accurate as a metagenome including the functional sequences themselves would be (Sun et al., 2020). Because we are reliant on 16S rRNA gene all KEGG ortholog $(\mathrm{KO})$ abundances are derived from the closest reference taxa that matches the supplied taxa. As such there may be significant differences between the KO of the actual organism and the reference we rely on.

To address this, we use PICRUSt2's nearest sequenced taxon index (NSTI) as a heuristic cutoff in the evaluation of taxon level functional analysis (Supplemental Table S3). Although we are using taxonomic families in this study, we will continue to use the NSTI cutoff of 0.15 , despite it being derived for species level comparisons. Where relevant, families with median NSTI scores within 1 standard deviation of 0.15 are labeled with an asterisk (*). Only one family, Pirellucae, was both significantly enriched in metabolic KOs while also having an NSTI outside of this range; this family was not included in the analysis.

KEGG Orthologs (KOs) were subsequently analyzed for significant (p-value $<=0.05$ ) differential abundances after centered log-ratio transformation (aldex.clr) using the general-linear model method (aldex.kw) of the ALDEx2 package (ver 1.18.0). These were then used for the construction of the heatmaps of KOs with differential abundance between pristine and impacted mangrove. Pathway analysis of these KOs was performed using KEGG Mapper (Kanehisa and Sato 2020). For a pathway to be considered we required that the entire pathway needed to be significantly enriched at a single site (i.e. 'complete').

\section{Differential abundance analysis}

In order to identify which taxa were significantly different in abundance in each sampling area we carried out a taxa enrichment analysis. ASV abundances were normalized by total sum scaling (TSS) wherein each ASV read abundance is reduced by a fraction so that the total sample is downsampled to match the least abundant sample in the experiment (Weiss et al. 2017). ASVs were combined into assigned taxa using the taxonomic results of QIIME2. To be defined as significantly different, several criteria must be met: there must be at least 100 unnormalized counts of the taxa in at least one site, the sets of observations between sites must be statistically significant ( $\mathrm{p}$-val $<=0.05$ ) as calculated using the Kruskal-Wallis $\mathrm{H}$ test and finally, the effect size must be in excess of a $20 \%$ difference in abundance between sites.

Since TSS normalization can confound interpretation, we also applied the same method to data that had been normalized using cumulative sum scaling (CSS). CSS is a normalization approach that weights the normalization factor based on the relative abundance of ASVs against the total abundance (Paulson et al. 2013). However, as we observed that this approach resulted in the loss of several common taxa and the gain of many more marginal taxa (Supplemental text S1) we chose to use the TSS normalization method.

A further extension of differential abundance is to identify taxa which are exclusive to a single site. In order to determine taxa exclusive to a single site with a high degree of certainty we required a taxon to have been observed 0 times (using unnormalized abundances) at one site and at least 100 counts at the other, with a minimum of 10 counts per replicate. 
260

261

262

263

264

265

266

267

268

269

270

271

272

273

274

275

276

277

278

279

280

281

282

283

284

285

286

287

288

289

290

291

292

293

294

295

296

297

298

299

300

301

302

303

Gneiss hierarchical clustering is an alternative approach that uses balance calculations to extend differential abundance analysis beyond species and instead identify niche specific subcommunities (Morton et al. 2017). Using this approach hundreds of taxa were found to be differentially abundant between the two sites (Supplemental Text S1) with all but 3 of our predicted differentially abundant taxa being present in the appropriate enriched cluster.

\section{Taxa specific predicted contribution to metabolic pathway functional abundances}

We calculated metabolic pathway enrichment specific to a given taxa at a given taxonomic level. For this we relied on the predicted relative functional abundance results of PICRUSt2. First, for each taxon, at each level, we combined all predicted relative functional abundances of KOs belonging to certain metabolic pathways: methane (ko00680), nitrogen (ko00910), sulfur (ko00920), and pentose phosphate (ko00030) metabolism - as well as, carbon fixation pathways in prokaryote (ko00720), carbon fixation pathways in photosynthetic organisms (ko00710), and photosynthesis (ko00195). We then applied Kruskal-Wallis $\mathrm{H}$ test to identify taxa that had significantly different taxa-specific pathway abundances. Furthermore, we require that a taxon at a single site must be significantly enriched relative to the other sites and that the taxa contributes at least $5 \%$ of the total relative functional abundance in at least one site.

The entire computational workflow is available as a repository in GitHub:

https://github.com/pspealman/Project_Impact.

The impacted mangrove sediment sequencing data is available from NCBI BioProject PRJNA650560, while the pristine mangrove sediment data is available from NCBI BioProject as accession number PRJNA608697.

\section{Results}

\section{Structural aspects of prokaryotic communities of mangrove sediments}

Taxonomic assignment of the prokaryotes in the mangrove samples resulted in a total of 7,278 ASVs (Supplemental Table S1), belonging to 1,369 taxa (Supplemental Table S2), 861 of which had at least 20 unnormalized reads in at least one site (Supplemental Text S1). These resolved to 184 taxa at the family level or higher, with 124 having at least 20 unnormalized reads at a single site. $60(48 \%)$ of these were present at both sites, while $13(11 \%)$ were unique to the conserved site, and $51(41 \%)$ were unique to the impacted site (Supplemental Text S1). Bacteria accounted for nearly $91 \%$ of all reads while archaeal taxa accounted for $7.9 \%$ and unassigned groups only $1.6 \%$. The two mangrove areas presented considerable differences at the phylum level for the 12 most abundant phyla. Figure 2 displays all the classes belonging to the top 12 phyla with more than $1 \%$ abundance in the analysis. Some phyla such as Firmicutes and Planctomycetes presented a large decrease in abundance in the impacted site when compared to the conserved site, while the presence of the entire phylum Euryarchaeota was only detected in the urbanized mangrove (Fig. 2). Some phyla were represented by different Classes in each site, as is the case of Chloroflexi, with Dehalococcoidia only prevailing in the impacted mangrove site. Below the family level we observed a dominance of unassigned groups (Supplemental Text S1).

The analysis revealed significantly higher richness (Total ASVs, Kruskal-Wallis $\mathrm{H}=3.857$, $\mathrm{df}=$ 1 , $\mathrm{p}$-value $=0.050$ ) and diversity (Shannon's diversity, Kruskal-Wallis $\mathrm{H}=3.857, \mathrm{df}=1$, $\mathrm{p}$-value $=$ 0.050 ) in the impacted mangrove sediments (Fig. 3A and 3B), relative to the conserved sediments. 
304

305

306

307

308

309

310

311

312

313

314

315

316

317

318

319

320

321

322

323

324

325

326

327

328

329

330

331

332

333

334

335

336

337

338

339

340

341

342

343

344

345

346

347

Additional alpha-diversity test results are available in Supplemental Text S1. Prokaryotic community composition differed between the two sites with marginal significance (PERMANOVA, permutations $=$ 999, pseudo-F $=3.285$, $p$-value $=0.096$ ), (see Supplemental Text S1 for additional beta-diversity tests) (Fig. 3C). Samples of each mangrove site form separate clusters as can be seen in the PCoA plot (Fig. 3D). The PCoA plot also shows that the samples from the conserved mangrove site present higher variability than the samples collected at the impacted site. The results showed a significant (p-value $<=$ 0.05 ) correlation between the structure of prokaryotic communities and some environmental variables (Supplemental Text S1). These include organic matter (conserved site mean: 3.8\%, impacted site mean: $9.9 \%$ ), temperature $\left(27.7^{\circ} \mathrm{C}, 29.3^{\circ} \mathrm{C}\right)$, and $\mathrm{Cu}(0 \mathrm{mg} \mathrm{Kg} \cdot, 0.16 \mathrm{mg} \mathrm{Kg} \cdot)$. While dissolved oxygen $(5.54 \mathrm{mg}$ $\left.\mathrm{L}^{-1}, 8.21 \mathrm{mg} \mathrm{L-1}\right), \mathrm{pH}(7.62,7.46), \mathrm{Ba}(0.66 \mathrm{mg} \mathrm{Kg}-1,0.44 \mathrm{mg} \mathrm{Kg} \cdot)$, and salinity (15.1 ppt, $\left.13.3 \mathrm{ppt}\right)$ were only marginally significant (p-value $<=0.1$ ) (Fig. 3D).

The majority of families with significant $(p<0.05)$ differences in abundances between sites were found in the sediments of the impacted mangrove. Figure 4 shows the 64 families with significant and large effect size differences between the sites ( $>20 \%)$ and those that are absent in one of the areas. We found 35 families that had significantly higher abundance in the impacted mangrove site, including human associated and human pathogen associated families Burkholderiaceae (Coenye 2014), Pasteurellaceae, Spirochaetaceae, Ruminococcaceae, Veillonellaceae, and Rikenellaceae. Also more prevalent in the impacted sediment were known archaeal methanogens Methanomicrobia and Thermoplasmata (Whitman, Bowen, and Boone 2014), Fe and Mn metabolizing Geobacteraceae (Röling 2014), and members of Gammaproteobacteria associated with sulfur metabolism Syntrophobacteraceae (Liu and Conrad 2017), Thioalkalispiraceae (Mori and Suzuki 2014), Saccharospirillaceae (Vavourakis et al. 2019), Thiomicrospiraceae (Eberhard et al. 1995); methanogen Methylomonaceae and nitrogen metabolising Nitrincolaceae. We also found Lachnospiraceae and Anaerolineae members of which were found to be of greater abundance in PVC contaminated environments (Seeley et al. 2020).

We also found 9 families with higher abundance in the conserved sediments. These include Thermoanaerobaculaceae, recently shown to have a high metabolic diversity in wastewater treatment plants (Kristensen et al. 2021), which along with Pirellulaceae, was recently found to be sensitive to microplastic pollution (Seeley et al. 2020). All enriched members of Planctomycetes, some of which are capable of anaerobic ammonia oxidation (anammox) have greater abundance at the conserved site, except MSBL9 SG8-4, potentially because of its freshwater preference (Andrei et al. 2019). We also observed the pathogen associated Vibrionaceae (Farmer 2006) in the area.

\section{Functional aspects of prokaryotic communities of mangrove sediment}

Functional profiles of the prokaryotic communities generated with PICRUSt2 based on the taxonomic abundances allowed us to identify statistically different potentials for carbon, nitrogen, phosphorus and sulfur metabolic pathways between the conserved and impacted mangrove sites (Fig. 5 and 6).

The carbon metabolism heatmaps are subdivided in: carbon fixation for photosynthetic organisms (ko00710), prokaryotes (ko00720) and methane (ko00680) metabolism, in order to allow a better visualization (Fig. 5). Generally, the methane and carbon fixation pathways presented higher functional abundance in the impacted site than that of the conserved mangrove. We found that the impacted site is enriched in the formaldehyde assimilation pathway (M00345), methane metabolism modules, (M00563) Methanogenesis, 2-Oxocarboxylic acid chain extension (M00608), light Crassulacean acid metabolism carbon fixation (M00169), and Serine biosynthesis (M00020).

Peer) reviewing PDF | (2021:04:60025:2:1:NEW 29 Aug 2021) 
348

349

350

351

352

353

354

355

356

357

358

359

360

361

362

363

364

365

366

367

368

369

370

371

372

373

374

375

376

377

378

379

380

381

382

383

384

385

386

387

388

389

390

391

The nitrogen metabolism heatmap (Fig. 6) presents enrichment of metabolic pathways in the impacted mangrove site, with a significant enrichment in the nitrogen to ammonia fixation module (M00175). The functional profile of pentose phosphate metabolism also shows a tendency for enrichment of KOs in the impacted mangrove area. This enrichment includes the pentose phosphate pathway (M00004), PRPP biosynthesis (M00005), both oxidative (M00006) and non-oxidative phases (M00007), the Entner-Doudoroff pathway (M00008), as well as the archaeal pathway (M00580). For sulfur metabolism, we found that some KOs are absent or nearly absent in the conserved sediments while generally present in the impacted area. In the conserved area, we found significant enrichment only in the cysteine biosynthesis (M00021) pathway. While photosynthesis associated KOs were relatively low, we did find significant enrichment in the conserved sediment for both photosystems I (M00163) and II (M00161), we also found that the impacted site is significantly enriched in F-type ATPase ATP synthesis (M00157). Taken together, these findings suggest that the high abundance and diversity in the impacted area leads to enrichment in several metabolic pathways, including several wholly absent from the conserved area.

We also analyzed the contribution each family makes to the metabolism of the elements $\mathrm{C}, \mathrm{N}, \mathrm{P}$ and S. Families that contribute $5 \%$ or more to a given nutrient cycle in at least one site are represented in Fig. 7. We found the majority of the families with large contributions to the metabolic pathways in the conserved mangrove sediments, which display the lower biodiversity. The families Bacillaceae and Stappiaceae were greatly important for nutrient metabolism in the conserved mangrove sediments but not in the impacted sediments. Conversely, only Syntrophaceae, and Desulfarculaceae presented large functional contributions for the impacted mangrove area. Anaerolineaceae and Desulfobacteraceae showed important contributions for the functional potentials in both studied areas. This is consistent with a lower biodiversity leading to a higher number of taxa making larger contributions to the total functional potential.

\section{Discussion}

Anthropogenic impacts are known to cause important changes both in structure and function of sediment microbiomes in mangroves (Ottoni et al. 2017; Imchen et al. 2018; Allard et al. 2020). In our study, we observed biodiversity to be higher in the impacted mangrove sediments than at the conserved site. Similar observations have been made previously in the comparison between conserved and anthropized mangrove areas in India (Fernandes et al. 2014) and the Red Sea region (Ullah et al. 2017). Here we find that organic matter is one of the most significant drivers of prokaryotic structuring between the measured environmental variables (Fig. 3). The large differences in organic matter contents could be the product of the urban runoff at the impacted site, which presented higher levels (median OM 9.9\%) in comparison with the conserved area (median OM 3.8\%). This suggests that this environment may have become more eutrophic due to the constant exposure to urban tailings, as observed in locu, which results in greater biomass production and biodiversity (Fernandes et al. 2014; Glibert 2017). While some studies that use incubation or microcosm approaches have observed decreasing microbial diversity as a result of nutrient addition, in experiments with coastal soils (Aoyagi et al 2015; Wang et al 2016; Bulseco et al 2019; Craig et al 2021), our study relied on field sediments which are continually exposed to anthropogenic presence, as such, would be expected to differ from controlled microcosms.

Besides organic matter, the structure of the prokaryotic communities in these mangrove sediments was greatly influenced by other environmental factors, such as temperature, copper content, $\mathrm{pH}$, salinity and barium concentrations (Fig. 3D). Some of these, such as salinity and $\mathrm{pH}$ are the result of

Peer] reviewing PDF | (2021:04:60025:2:1:NEW 29 Aug 2021) 
392

393

394

395

396

397

398

399

400

401

402

403

404

405

406

407

408

409

410

411

412

413

414

415

416

417

418

419

420

421

422

423

424

425

426

427

428

429

430

431

432

433

434

435

naturally driven biogeochemical processes in the area, while others, such as metal content, were observed to reflect the natural lithology of the estuary area (Pereira 2016) or tidal deposition, as is the case with Ba (Carneiro et al. 2021).

Beyond the presence of an urban complex, other differences exist between the two sites as they are located along a gradient from river source to ocean. Notably, the increasing salinity due to proximity to the sea can impair the bioavailability of organic matter in these sediments, consequently affecting the availability of nutrients (Filippino et al. 2011). The different sources of dissolved and particulate OM in aquatic environments also have large effects on the contents, species, and availability of nutrients such as $\mathrm{N}, \mathrm{P}$, and heavy metals (Dong et al. 2020). Although mangrove species show an optimal growth over a large range of salinity (Krauss 2008), and the differences observed in this study are small, all these factors may interact synergistically with the observed anthropogenic impacts, such as deforestation and construction byproducts, as well as urban tailings, to create a completely different sediment environment.

We sought to identify differences in the metabolic systems of the two sites using functional profiling. However, the functional profiles were not obtained by metagenomic sequencing, but based on the abundances of identified taxa compared to a reference holotype. To highlight this important limitation, we refer to these functional profiles as potential metabolic abundances. Although the use of metagenomic sequencing can provide better resolution to functional profiling (Zhang et al., 2021), it is possible to recover the general patterns of the microbiome functions through the taxonomic abundances of the $16 \mathrm{~S}$ rRNA genes (Jovel et al., 2016). The diversity of taxa contributing to the metabolic pathways of the studied nutrient cycles is in accordance with the premise that soil and sediment microbial communities present elevated functional versatility (Barnes, Carter, and Lewis 2020), where many taxonomic groups can play considerable roles in a variety of functions.

We observed that the potential functional abundance for the metabolism of specific elements were spread across taxa as a function of biodiversity. Specifically, the impacted site, with a higher number of taxonomic groups, had fewer taxa making large contributions $(>5 \%)$ to the metabolic potentials, while the conserved site with low diversity showed a higher number of families contributing greatly to such metabolisms. Some taxa, such as Desulfobacterales, an important sulfate-reducing bacteria, have been previously shown to contribute greatly with important nutrient metabolisms in mangrove sediments (Ullah et al. 2017; Nie et al. 2021). This is in accordance with our results where the Desulfobacterales taxa was also an important contributor to carbon and nitrogen metabolisms in both mangrove areas (Fig. 7). Taken together the results support the conclusion that, the lower the biodiversity, the higher the importance of particular groups to the nutrient cycles.

Considering that the conserved site shows that a large portion of the ecosystem function is dependent on a small number of taxa and that large differences exist between the taxa of the two sites, it may be expected that the urbanization process and the subsequent disturbance in the microbiome population would lead to an imbalance in nutrient cycling, potentially impairing some important metabolisms. The analysis of functional profiles suggests, however, the opposite trend where the functional potentials for these metabolisms are higher in the impacted mangrove site. Despite this increased metabolic activity at the impacted site, the ultimate effect these changes have on metabolic output, such as carbon sequestration or methane production, is difficult to predict. Previous work has shown that the increased consumption of carbon may not lead to increased sequestration as increased decomposition may lead to lower carbon burial rates (Bulseco 2019).

Furthermore, the potential maintenance of the KOs and modules that make up nutrient cycles is not a guarantee of a healthy ecosystem. Changes in nutrient availability caused by human interference 
436 have previously been shown to affect the diversity of sulfate-reducing (SRB) and sulfur-oxidizing

437

438

439

440

441

442

443

444

445

446

447

448

449

450

451

452

453

454

455

456

457

458

459

460

461

462

463

464

465

466

467

468

469

470

471

472

473

474

475

476

477

478

bacteria (SOB) (Meyer et al. 2016), thus interfering in the cycling of this element. Indeed, we see numerous prokaryotic species negatively affected by human impacts and there is great potential for eukaryotic species to be impacted as well. The alteration in microbiome nutrient cycling driven by urbanization is potentially hazardous as it can increase primary production, leading to a higher spatial and temporal hypoxia in the aquatic environment (Houser and Richardson 2010), resulting in a cascading effect in the system. Although Camamu Bay is a well conserved coastal system, it does contain low abundances of toxic cyanobacteria, such as Microcystis, that have the potential to form blooms in eutrophic waters, which, in turn, is consistent with habitat degradation trends reported in estuaries worldwide (Affe et al. 2018).

In this work we found widespread variance in taxa abundance between sites up to and including the possible extinction of families at the impacted site (Fig. 4). Although the majority of taxa observed at the conserved site persisted in the impacted site, some families could be identified only in the conserved sediments. Here, we consider the absence of groups in the impacted site as indicative of a possible local extinction caused by human interference. The absences of some families are consistent with local extinction driven by anthropogenic change, such as subgroup 9 of Acidobacteria, which despite having a relatively high abundance at the conserved site is entirely absent from the impacted site. Notably many members of this taxa are known to be oligotrophic with a strong negative correlation with the organic carbon in the environment (Kielak et al. 2016). Conversely, for some families, such as Caldilineaceae and Rubritaleaceae, whose ecological aspects are still not well documented, their absence in the impacted mangrove suggests that these groups could also be oligotrophic or sensitive to some components of urban pollution, warranting further studies.

Similarly, some of the taxa that were enriched or unique for the impacted mangrove area could be directly correlated with the discharge of domestic sewage in the area. The prevalence of the family Pasteurellaceae is an example, since most of its subgroups are known pathogens of vertebrates and are not usually found outside hosts (Christensen et al. 2014). Additionally, many genera belonging to the family Spirochaetaceae are known for causing a variety of human diseases such as syphilis, Lyme disease, leptospirosis, and periodontal disease, among others (Karami et al. 2014). Furthermore, members of the Ruminococcaceae are among the most abundant groups found in the mammalian gut environment (Biddle et al. 2013). Veillonellaceae is a diverse family with varying degrees of antimicrobial resistance and is associated with disease in both animals and humans (Marchandin and Jumas-Bilak 2014). Finally, the enrichment in the Rikenellaceae family could be further evidence of fecal contamination, as the presence of subgroups of Bacteroidales has been proposed as a predictor of the risk of waterborne diseases (Schriewer et al. 2010).

In addition to the concerns about the prevalence of known human and animal pathogenic groups, recent studies have also shown the dissemination of antibiotic resistance genes in diverse mangrove compartments, including the sediment-root continuum, with antibiotic resistance sorting independently of the associate microbiota (Wang et al. 2021; Imchen and Kumavath 2021). Antibiotic resistance itself is highly correlated with anthropogenic interference in mangroves, which is in turn strongly determined by local socioeconomic factors (Imchen and Kumavath 2021). In this sense, the anthropogenic impacts in mangrove ecosystems can lead to consequences beyond the ecosystem threats and health risks for the local human population, but it can potentially increase global health threats with the spread of antibiotic resistance in pathogenic microbes.

Peer] reviewing PDF | (2021:04:60025:2:1:NEW 29 Aug 2021) 
479

480

481

482

483

484

485

486

487

488

489

490

491

492

493

494

495

496

497

498

499

500

501

502

503

504

505

506

507

508

509

510

511

512

513

514

515

516

517

518

519

520

521

522

We also observed that the variance in communities between replicates was greater in the conserved samples. While this could represent higher diversity in conserved microbiomes, other factors could potentially play a role. Importantly sample collection at the conserved site spanned a larger distance with $15 \mathrm{~m}$ instead of $5 \mathrm{~m}$ separating the sample sites, and there was a more pronounced separation of tidal zones as well. The small number of samples is also a relevant limitation, especially for matters of statistical analysis. Additionally, the two sites, although sharing the same watershed and estuary, were $\sim 10 \mathrm{Km}$ apart, and as such, numerous environmental differences may contribute to the variance as well. Nevertheless, the largest difference observed in physical parameters was the presence/absence of urbanization at the site. Considering that the samples from the impacted area were collected nearby domestic runoff sources, while the conserved site presented no signs of anthropogenic impact, and that some of the taxa uniquely found in the impacted sediments are recognized as pathogenic and gut microbiome colonizers, we consider that these important differences are correlated with the observed human impacts.

Our results show that the microbial communities of sediments can be largely affected by land use in mangrove adjacent areas, and that the observation of some particular prokaryotic groups are potential bioindicators of such human impacts, as well as posing risks to the surrounding populations. Notably, Brazilian mangroves are currently under elevated risk due to recent changes in the environmental legislation in the nation. Therefore, decision making organizations should be aware of the sensitivity of the microbiomes in this ecosystem, which play such important roles in the larger biogeochemical cycles, thus affecting global nutrient cycling, and act towards the conservation of the mangroves.

\section{Conclusions}

Our study looked at the effects of urbanization on the prokaryotic communities of mangrove sediments, through a comparison of samples taken from both impacted and conserved areas of the same estuarine system. The analysis found a statistically relevant change in the structure of the communities and an elevation of prokaryotic biodiversity in the sediments of the urbanized mangrove area. The predicted functional analysis showed that the general patterns of nutrient metabolisms could be maintained and that the metabolic potentials in the impacted mangrove were higher than in conserved mangroves, likely due to the higher biodiversity present in the impacted area. The observation of diverse groups contributing to metabolic pathways suggests higher versatility in the impacted mangrove sediments, where the functions are carried out by a greater number of groups, while fewer groups are responsible for large functional contributions in the conserved site. Beyond the differing nature of the sources of organic compounds and clear physical impacts between the areas, other environmental factors also played a significant role in the structure of the microbial communities. Notably, some of these may act synergistically to create the different patterns observed. Despite increasing biodiversity on the mangrove ecosystem, the presence of an urban settlement showed some clear negative effects, such as the extinction of some prokaryotic groups, as well as the colonization by human and animal pathogens in the microbiome of the impacted area. In this sense, the relative stability observed in functional terms does not imply the absence of a negative impact and recent studies confirm that human interference can lead to the spread of antibiotic resistance in mangrove sediments, which can cause serious health issues globally. This study provides evidence that the impacts of urbanization are reflected also in microbiological scales inducing important changes in ecosystem functions that could, in turn, impact the biogeochemical cycles in larger scales if not monitored and controlled. Future microbiome studies should be expanded to include eukaryotes, fungi, and viruses for a more complete profile of the microbial populations in these areas. 
523 Direct measurements of carbon, contaminants, and nutrient cycling rates in the field would also be

524 valuable to verify the functional profiling results obtained in this work.

525

526

527

528

529

\section{Acknowledgements}

The authors would like to thank the Organização de Conservação da Terra (OCT) for providing the structure for the field work in the environmental protection area, and the sequencing facility of the Microbial Ecology and Biotechnology Laboratory (LEMBiotec).

530

\section{References}

532

533

534

535

536

537

538

539

540

541

542

543

544

545

546

Affe HM de J, Rigonato J, Nunes JM de C, Menezes M. 2018. Metagenomic Analysis of Cyanobacteria in an Oligotrophic Tropical Estuary, South Atlantic. Frontiers in microbiology 9:1393. DOI: 10.3389/fmicb.2018.01393.

Allard SM, Costa MT, Bulseco AN, Helfer V, Wilkins LGE, Hassenrück C, Zengler K, Zimmer M, Erazo N, Mazza Rodrigues JL, Duke N, Melo VMM, Vanwonterghem I, Junca H, Makonde HM, Jiménez DJ, Tavares TCL, Fusi M, Daffonchio D, Duarte CM, Peixoto RS, Rosado AS, Gilbert JA, Bowman J. 2020. Introducing the Mangrove Microbiome Initiative: Identifying Microbial Research Priorities and Approaches To Better Understand, Protect, and Rehabilitate Mangrove Ecosystems. mSystems 5. DOI: $10.1128 /$ msystems.00658-20.

Anderson MJ. 2006. Distance-based tests for homogeneity of multivariate dispersions. Biometrics 62:245-253. DOI: 10.1111/j.1541-0420.2005.00440.x.

Andrei A-Ş, Salcher MM, Mehrshad M, Rychtecký P, Znachor P, Ghai R. 2019. Niche-directed evolution modulates genome architecture in freshwater Planctomycetes. The ISME journal 13:1056-1071. DOI: 10.1038/s41396-018-0332-5.

Andreote FD, Jiménez DJ, Chaves D, Dias ACF, Luvizotto DM, Dini-Andreote F, Fasanella CC, Lopez MV, Baena S, Taketani RG, de Melo IS. 2012. The microbiome of Brazilian mangrove sediments as revealed by metagenomics. PloS one 7:e38600. DOI: 10.1371/journal.pone.0038600.

Aoyagi T, Kimura M, Yamada N, Navarro RR, Itoh H, Ogata A, Sakoda A, Katayama Y, Takasaki M, Hori T. 2015. Dynamic transition of chemolithotrophic sulfur-oxidizing bacteria in response to amendment with nitrate in deposited marine sediments. Frontiers in microbiology 6:426. DOI: 10.3389/fmicb.2015.00426.

Barbera P, Kozlov AM, Czech L, Morel B, Darriba D, Flouri T, Stamatakis A. 2019. EPA-ng: Massively Parallel Evolutionary Placement of Genetic Sequences. Systematic biology 68:365-369. DOI: 10.1093/sysbio/syy054.

Barnes EM, Carter EL, Lewis JD. 2020. Predicting Microbiome Function Across Space Is Confounded by Strain-Level Differences and Functional Redundancy Across Taxa. Frontiers in microbiology 11:101. DOI: $10.3389 /$ fmicb.2020.00101.

Biddle A, Stewart L, Blanchard J, Leschine S. 2013. Untangling the Genetic Basis of Fibrolytic Specialization by Lachnospiraceae and Ruminococcaceae in Diverse Gut Communities. Diversity 5:627-640. DOI: 10.3390/d5030627.

Bokulich NA, Kaehler BD, Rideout JR, Dillon M, Bolyen E, Knight R, Huttley GA, Gregory Caporaso J. 2018. Optimizing taxonomic classification of marker-gene amplicon sequences with QIIME 2's q2feature-classifier plugin. Microbiome 6:90. DOI: 10.1186/s40168-018-0470-z. 
565

566

567

568

569

570

571

572

573

574

575

576

577

578

579

580

581

582

583

584

585

586

587

588

589

590

591

592

593

594

595

596

597

598

599

600

601

602

603

604

605

606

607

608

Bolger AM, Lohse M, Usadel B. 2014. Trimmomatic: a flexible trimmer for Illumina sequence data. Bioinformatics 30:2114-2120. DOI: 10.1093/bioinformatics/btu170.

Bolyen E, Rideout JR, Dillon MR, Bokulich NA, Abnet CC, Al-Ghalith GA, Alexander H, Alm EJ, Arumugam M, Asnicar F, Bai Y, Bisanz JE, Bittinger K, Brejnrod A, Brislawn CJ, Brown CT, Callahan BJ, Caraballo-Rodríguez AM, Chase J, Cope EK, Da Silva R, Diener C, Dorrestein PC, Douglas GM, Durall DM, Duvallet C, Edwardson CF, Ernst M, Estaki M, Fouquier J, Gauglitz JM, Gibbons SM, Gibson DL, Gonzalez A, Gorlick K, Guo J, Hillmann B, Holmes S, Holste H, Huttenhower C, Huttley GA, Janssen S, Jarmusch AK, Jiang L, Kaehler BD, Kang KB, Keefe CR, Keim P, Kelley ST, Knights D, Koester I, Kosciolek T, Kreps J, Langille MGI, Lee J, Ley R, Liu YX, Loftfield E, Lozupone C, Maher M, Marotz C, Martin BD, McDonald D, McIver LJ, Melnik AV, Metcalf JL, Morgan SC, Morton JT, Naimey AT, Navas-Molina JA, Nothias LF, Orchanian SB, Pearson T, Peoples SL, Petras D, Preuss ML, Pruesse E, Rasmussen LB, Rivers A, Robeson MS 2nd, Rosenthal P, Segata N, Shaffer M, Shiffer A, Sinha R, Song SJ, Spear JR, Swafford AD, Thompson LR, Torres PJ, Trinh P, Tripathi A, Turnbaugh PJ, Ul-Hasan S, van der Hooft JJJ, Vargas F, Vázquez-Baeza Y, Vogtmann E, von Hippel M, Walters W, Wan Y, Wang M, Warren J, Weber KC, Williamson CHD, Willis AD, Xu ZZ, Zaneveld JR, Zhang Y, Zhu Q, Knight R, Caporaso JG. 2019. Reproducible, interactive, scalable and extensible microbiome data science using QIIME 2. Nature biotechnology 37:852-857. DOI: 10.1038/s41587-019-0209-9.

Bulseco AN, Giblin AE, Tucker J, Murphy AE, Sanderman J, Hiller-Bittrolff K, Bowen JL. 2019. Nitrate addition stimulates microbial decomposition of organic matter in salt marsh sediments. Global Change Biology 25:3224-3241. DOI: 10.1111/gcb.14726.

Cabral L, Júnior GVL, Pereira de Sousa ST, Dias ACF, Lira Cadete L, Andreote FD, Hess M, de Oliveira VM. 2016. Anthropogenic impact on mangrove sediments triggers differential responses in the heavy metals and antibiotic resistomes of microbial communities. Environmental Pollution 216:460-469.

DOI: 10.1016/j.envpol.2016.05.078.

Caporaso J, Lauber CL, Walters WA, Berg-Lyons D, Huntley J, Fierer N, Owens SM, Betley J, Fraser L, Bauer M, Gormley N, Gilbert JA, Smith G, Knight R. 2012. Ultra-high-throughput microbial community analysis on the Illumina HiSeq and MiSeq platforms. The ISME journal 6:1621-1624. DOI: $10.1038 /$ ismej.2012.8.

Caporaso JG, Lauber CL, Walters WA, Berg-Lyons D, Lozupone CA, Turnbaugh PJ, Fierer N, Knight R. 2011. Global patterns of 16S rRNA diversity at a depth of millions of sequences per sample.

Proceedings of the National Academy of Sciences of the United States of America 108 Suppl 1:45164522. DOI: $10.1073 /$ pnas. 1000080107.

Carneiro LM, Dourado GB, de Carvalho CEV, da Silva Júnior JB, de Jesus TB, Hadlich GM. 2021. Evaluation of the concentrations of elements at trace level in the Serinhaem River estuary, Bahia, Brazil, using chemometric tools. Marine pollution bulletin 163:111953. DOI: 10.1016/j.marpolbul.2020.111953.

Christensen H, Kuhnert P, Nørskov-Lauritsen N, Planet PJ, Bisgaard M. 2014. The Family Pasteurellaceae. The Prokaryotes:535-564. DOI: 10.1007/978-3-642-38922-1_224.

Coenye T. 2014. The Family Burkholderiaceae. In: Rosenberg E, DeLong EF, Lory S, Stackebrandt E, Thompson F eds. The Prokaryotes: Alphaproteobacteria and Betaproteobacteria. Berlin, Heidelberg: Springer Berlin Heidelberg, 759-776. DOI: 10.1007/978-3-642-30197-1_239.

CONAMA. Conselho Nacional de Meio Ambiente. 2002. Resolução CONAMA nº. 303, de 20 de março de 2002.

Peer] reviewing PDF | (2021:04:60025:2:1:NEW 29 Aug 2021) 
609

610

611

612

613

614

615

616

617

618

619

620

621

622

623

624

625

626

627

628

629

630

631

632

633

634

635

636

637

638

639

640

641

642

643

644

645

646

647

648

649

650

651

Craig H, Antwis RE, Cordero I, Ashworth D, Robinson CH, Osborne TZ, Bardgett RD, Rowntree JK, Simpson LT. 2021. Nitrogen addition alters composition, diversity, and functioning of microbial communities in mangrove soils: An incubation experiment. Soil biology \& biochemistry 153:108076. DOI: $10.1016 /$ j.soilbio.2020.108076.

Czech L, Barbera P, Stamatakis A. 2020. Genesis and Gappa: processing, analyzing and visualizing phylogenetic (placement) data. Bioinformatics . DOI: 10.1093/bioinformatics/btaa070.

Ditt E, Zysman N, Cunha RS da, Rocha RB da. 2013. Conservação Da Biodiversidade Por Meio Da Atividade Extrativista Em Comunidades Quilombolas. Revista Brasileira de Ciências Ambientais 27.

Dixon P. 2003. VEGAN, a package of R functions for community ecology. Journal of Vegetation Science 14:927. DOI: 10.1658/1100-9233(2003)014[0927:vaporf]2.0.co;2.

Dong Y, Li Y, Kong F, Zhang J, Xi M. 2020. Source, structural characteristics and ecological indication of dissolved organic matter extracted from sediments in the primary tributaries of the Dagu River. Ecological Indicators 109:105776. DOI: 10.1016/j.ecolind.2019.105776.

Douglas GM, Maffei VJ, Zaneveld J, Yurgel SN, Brown JR, Taylor CM, Huttenhower C, Langille MGI. 2019. PICRUSt2: An improved and extensible approach for metagenome inference. Bioinformatics:497.

Eberhard C, Wirsen CO, Jannasch HW. 1995. Oxidation of polymetal sulfides by chemolithoautotrophic bacteria from deep-sea hydrothermal vents. Geomicrobiology journal 13:145-164. DOI: 10.1080/01490459509378014.

Farmer JJ. 2006. The Family Vibrionaceae. In: Dworkin M, Falkow S, Rosenberg E, Schleifer K-H, Stackebrandt E eds. The Prokaryotes: A Handbook on the Biology of Bacteria Volume 6: Proteobacteria: Gamma Subclass. New York, NY: Springer New York, 495-507. DOI: 10.1007/0387-30746-X_17.

Fernandes SO, Kirchman DL, Michotey VD, Bonin PC, LokaBharathi PA. 2014. Bacterial diversity in relatively pristine and anthropogenically-influenced mangrove ecosystems (Goa, India). Brazilian journal of microbiology: [publication of the Brazilian Society for Microbiology] 45:1161-1171. DOI: 10.1590/s1517-83822014000400006.

Filippino KC, Mulholland MR, Bernhardt PW, Boneillo GE, Morse RE, Semcheski M, Marshall H, Love NG, Roberts Q, Bronk DA. 2011. The bioavailability of effluent-derived organic nitrogen along an estuarine salinity gradient. Estuaries and coasts: journal of the Estuarine Research Federation 34:269-280. DOI: 10.1007/s12237-010-9314-1.

Giri C, Ochieng E, Tieszen LL, Zhu Z, Singh A, Loveland T, Masek J, Duke N. 2011. Status and distribution of mangrove forests of the world using earth observation satellite data. Global ecology and biogeography: a journal of macroecology 20:154-159. DOI: 10.1111/j.1466-8238.2010.00584.x. Glibert PM. 2017. Eutrophication, harmful algae and biodiversity - Challenging paradigms in a world of complex nutrient changes. Marine pollution bulletin 124:591-606. DOI: 10.1016/j.marpolbul.2017.04.027.

Gong B, Cao H, Peng C, Perčulija V, Tong G, Fang H, Wei X, Ouyang S. 2019. High-throughput sequencing and analysis of microbial communities in the mangrove swamps along the coast of Beibu Gulf in Guangxi, China. Scientific reports 9:9377. DOI: 10.1038/s41598-019-45804-w.

Houser JN, Richardson WB. 2010. Nitrogen and phosphorus in the Upper Mississippi River: transport, processing, and effects on the river ecosystem. Hydrobiologia 640:71-88. DOI: 10.1007/s10750-0090067-4.

Peer] reviewing PDF | (2021:04:60025:2:1:NEW 29 Aug 2021) 
652

653

654

655

656

657

658

659

660

661

662

663

664

665

666

667

668

669

670

671

672

673

674

675

676

677

678

679

680

681

682

683

684

685

686

687

688

689

690

691

692

693

694

Howard J, Sutton-Grier A, Herr D, Kleypas J, Landis E, Mcleod E, Pidgeon E, Simpson S. 2017. Clarifying the role of coastal and marine systems in climate mitigation. Frontiers in Ecology and the Environment 15:42-50. DOI: 10.1002/fee.1451.

IBGE - INSTITUTO BRASILEIRO DE GEOGRAFIA E ESTATÍSTICA. 2020. Censo Brasileiro de 2019. Rio de Janeiro: IBGE

Imchen M, Kumavath R. 2021. Metagenomic insights into the antibiotic resistome of mangrove sediments and their association to socioeconomic status. Environmental pollution 268:115795. DOI: 10.1016/j.envpol.2020.115795.

Imchen M, Kumavath R, Barh D, Azevedo V, Ghosh P, Viana M, Wattam AR. 2017. Searching for signatures across microbial communities: Metagenomic analysis of soil samples from mangrove and other ecosystems. Scientific reports 7:8859. DOI: 10.1038/s41598-017-09254-6.

Imchen M, Kumavath R, Barh D, Vaz A, Góes-Neto A, Tiwari S, Ghosh P, Wattam AR, Azevedo V. 2018. Comparative mangrove metagenome reveals global prevalence of heavy metals and antibiotic resistome across different ecosystems. Scientific reports 8:11187. DOI: 10.1038/s41598-018-295214.

Kanehisa M, Sato Y. 2020. KEGG Mapper for inferring cellular functions from protein sequences. Protein science: a publication of the Protein Society 29:28-35. DOI: 10.1002/pro.3711.

Karami A, Sarshar M, Ranjbar R, Zanjani RS. 2014. The Phylum Spirochaetaceae. In: Rosenberg E, DeLong EF, Lory S, Stackebrandt E, Thompson F eds. The Prokaryotes. Berlin, Heidelberg: Springer Berlin Heidelberg, 915-929. DOI: 10.1007/978-3-642-38954-2_156.

Kielak AM, Barreto CC, Kowalchuk GA, van Veen JA, Kuramae EE. 2016. The Ecology of Acidobacteria: Moving beyond Genes and Genomes. Frontiers in microbiology 7:744. DOI: 10.3389/fmicb.2016.00744.

Kozich JJ, Westcott SL, Baxter NT, Highlander SK, Schloss PD. 2013. Development of a dual-index sequencing strategy and curation pipeline for analyzing amplicon sequence data on the MiSeq Illumina sequencing platform. Applied and environmental microbiology 79:5112-5120. DOI: 10.1128/AEM.01043-13.

Kristensen JM, Singleton C, Clegg L-A, Petriglieri F, Nielsen PH. 2021. High Diversity and Functional Potential of Undescribed "Acidobacteriota" in Danish Wastewater Treatment Plants. Frontiers in microbiology 12:643950. DOI: 10.3389/fmicb.2021.643950.

Lin X, Hetharua B, Lin L, Xu H, Zheng T, He Z, Tian Y. 2019. Mangrove Sediment Microbiome: Adaptive Microbial Assemblages and Their Routed Biogeochemical Processes in Yunxiao Mangrove National Nature Reserve, China. Microbial ecology 78:57-69. DOI: 10.1007/s00248-018-1261-6.

Liu P, Conrad R. 2017. Syntrophobacteraceae-affiliated species are major propionate-degrading sulfate reducers in paddy soil. Environmental microbiology 19:1669-1686. DOI: 10.1111/1462-2920.13698.

Lopes NS. 2011. Análise da paisagem com base na fragmentação - caso APA do Pratigi, baixo sul da Bahia, Brasil. Revista Eletrônica do Prodema 6:53-67.

Louca S, Doebeli M. 2018. Efficient comparative phylogenetics on large trees. Bioinformatics 34:10531055. DOI: 10.1093/bioinformatics/btx701.

Macreadie PI, Anton A, Raven JA, Beaumont N, Connolly RM, Friess DA, Kelleway JJ, Kennedy H, Kuwae T, Lavery PS, Lovelock CE, Smale DA, Apostolaki ET, Atwood TB, Baldock J, Bianchi TS, Chmura GL, Eyre BD, Fourqurean JW, Hall-Spencer JM, Huxham M, Hendriks IE, Krause-Jensen D, Laffoley D, Luisetti T, Marbà N, Masque P, McGlathery KJ, Megonigal JP, Murdiyarso D, Russell

Peer] reviewing PDF | (2021:04:60025:2:1:NEW 29 Aug 2021) 
695

696

697

698

699

700

701

702

703

704

705

706

707

708

709

710

711

712

713

714

715

716

717

718

719

720

721

722

723

724

725

726

727

728

729

730

731

732

733

734

735

736

737

738

BD, Santos R, Serrano O, Silliman BR, Watanabe K, Duarte CM. 2019. The future of Blue Carbon science. Nature communications 10:3998. DOI: 10.1038/s41467-019-11693-w.

Marchandin H, Jumas-Bilak E. 2014. The Family Veillonellaceae. In: Rosenberg E, DeLong EF, Lory S, Stackebrandt E, Thompson F eds. The Prokaryotes: Firmicutes and Tenericutes. Berlin, Heidelberg: Springer Berlin Heidelberg, 433-453. DOI: 10.1007/978-3-642-30120-9_361.

Marcos MS, Barboza AD, Keijzer RM, Laanbroek HJ. 2018. Tide as Steering Factor in Structuring Archaeal and Bacterial Ammonia-Oxidizing Communities in Mangrove Forest Soils Dominated by Avicennia germinans and Rhizophora mangle. Microbial ecology 75:997-1008. DOI:

10.1007/s00248-017-1091-y.

Mascarenhas RB, Aragão IR, Reis P, de Jesus Bomfim T. 2019. ANÁLISE DE METAIS-TRAÇOS EM SEDIMENTOS DA APA DO PRATIGI, BAHIA. Sitientibus. Serie Ciencias Biologicas 0. DOI: 10.13102/sitientibus.v0i53.4467.

McDonald D, Price MN, Goodrich J, Nawrocki EP, DeSantis TZ, Probst A, Andersen GL, Knight R, Hugenholtz P. 2012. An improved Greengenes taxonomy with explicit ranks for ecological and evolutionary analyses of bacteria and archaea. The ISME journal 6:610-618. DOI: 10.1038/ismej.2011.139.

MDMA, Ministério do Meio Ambiente. 2010. Plano Territorial de Desenvolvimento Sustentável do Território Baixo Sul da Bahia. http://sit.mda.gov.br/download/ptdrs/ptdrs_qua_territorio021.pdf

Meyer DD, de Andrade PAM, Durrer A, Andreote FD, Corção G, Brandelli A. 2016. Bacterial communities involved in sulfur transformations in wastewater treatment plants. Applied microbiology and biotechnology 100:10125-10135. DOI: 10.1007/s00253-016-7839-3.

MMA, Ministério do Meio Ambiente. 2004. Plano de Manejo da APA do Pratigi - Encarte II Zoneamento e Plano de Gestao.

Moitinho MA, Bononi L, Souza DT, Melo IS, Taketani RG. 2018. Bacterial Succession Decreases Network Complexity During Plant Material Decomposition in Mangroves. Microbial ecology 76:954-963. DOI: 10.1007/s00248-018-1190-4.

Mori K, Suzuki K-I. 2014. The Family Thioalkalispiraceae. In: Rosenberg E, DeLong EF, Lory S, Stackebrandt E, Thompson F eds. The Prokaryotes: Gammaproteobacteria. Berlin, Heidelberg: Springer Berlin Heidelberg, 653-658. DOI: 10.1007/978-3-642-38922-1_399.

Morton JT, Sanders J, Quinn RA, McDonald D, Gonzalez A, Vázquez-Baeza Y, Navas-Molina JA, Song SJ, Metcalf JL, Hyde ER, Lladser M, Dorrestein PC, Knight R. 2017. Balance Trees Reveal Microbial Niche Differentiation. mSystems 2. DOI: 10.1128/mSystems.00162-16.

Nelson DW, Sommers LE. 1996. Total Carbon, Organic Carbon, and Organic Matter: Part 3 Chemical Methods. In: Sparks DL, Page AL, Helmke PA, Loeppert RH, Soltanpour PN, Tabatabai MA, Johnston CT, Sumner ME eds. Methods of Soil Analysis. SSSA Book Series. Madison, WI, USA: Soil Science Society of America, American Society of Agronomy, 961-1010. DOI: 10.2136/sssabookser5.3.c34.

Nesme J, Achouak W, Agathos SN, Bailey M, Baldrian P, Brunel D, Frostegård Å, Heulin T, Jansson JK, Jurkevitch E, Kruus KL, Kowalchuk GA, Lagares A, Lappin-Scott HM, Lemanceau P, Le Paslier D, Mandic-Mulec I, Murrell JC, Myrold DD, Nalin R, Nannipieri P, Neufeld JD, O'Gara F, Parnell JJ, Pühler A, Pylro V, Ramos JL, Roesch LFW, Schloter M, Schleper C, Sczyrba A, Sessitsch A, Sjöling S, Sørensen J, Sørensen SJ, Tebbe CC, Topp E, Tsiamis G, van Elsas JD, van Keulen G, Widmer F, Wagner M, Zhang T, Zhang X, Zhao L, Zhu Y-G, Vogel TM, Simonet P. 2016. Back to the Future of Soil Metagenomics. Frontiers in microbiology 7:73. DOI: 10.3389/fmicb.2016.00073.

Peer] reviewing PDF | (2021:04:60025:2:1:NEW 29 Aug 2021) 
739

740

741

742

743

744

745

746

747

748

749

750

751

752

753

754

755

756

757

758

759

760

761

762

763

764

765

766

767

768

769

770

771

772

773

774

775

776

777

778

779

780

781

782

Nie S, Zhang Z, Mo S, Li J, He S, Kashif M, Liang Z, Shen P, Yan B, Jiang C. 2021. Desulfobacterales stimulates nitrate reduction in the mangrove ecosystem of a subtropical gulf. The Science of the total environment 769:144562. DOI: 10.1016/j.scitotenv.2020.144562.

Ottoni JR, Cabral L, de Sousa STP, Júnior GVL, Domingos DF, Soares Junior FL, da Silva MCP, Marcon J, Dias ACF, de Melo IS, de Souza AP, Andreote FD, de Oliveira VM. 2017. Functional metagenomics of oil-impacted mangrove sediments reveals high abundance of hydrolases of biotechnological interest. World journal of microbiology \& biotechnology 33:141. DOI: 10.1007/s11274-017-2307-5.

Parada AE, Needham DM, Fuhrman JA. 2016. Every base matters: assessing small subunit rRNA primers for marine microbiomes with mock communities, time series and global field samples. Environmental microbiology 18:1403-1414. DOI: 10.1111/1462-2920.13023.

Paulson JN, Stine OC, Bravo HC, Pop M. 2013. Differential abundance analysis for microbial markergene surveys. Nature methods 10:1200-1202. DOI: 10.1038/nmeth.2658.

Pereira M. 2016. Espacialização geoquímica dos sedimentos do estuário do Rio Serinhaém, baixo sul da Bahia - Brasil / geochemical spacialization of the sediments of the Rio Serinhaém estuary, lower south of Bahia - Brazil. Programa de Pós-Graduação em Modelagem em Ciências da Terra e do Ambiente - PPGM Thesis. Universidade Estadual de Feira de Santana.

R Core Team. 2019. R: A Language and Environment for Statistical Computing.

Ribeiro M, Aguiar WM, Nunes LA, Carneiro LDS. 2019. Morphometric Changes in Three Species of Euglossini (Hymenoptera: Apidae) in Response to Landscape Structure. DOI: 10.13102/sociobiology.v66i2.3779.

Röling WFM. 2014. The Family Geobacteraceae. In: Rosenberg E, DeLong EF, Lory S, Stackebrandt E, Thompson F eds. The Prokaryotes: Deltaproteobacteria and Epsilonproteobacteria. Berlin, Heidelberg: Springer Berlin Heidelberg, 157-172. DOI: 10.1007/978-3-642-39044-9_381.

Sanders CJ, Eyre BD, Santos IR, Machado W, Luiz-Silva W, Smoak JM, Breithaupt JL, Ketterer ME, Sanders L, Marotta H, Silva-Filho E. 2014. Elevated rates of organic carbon, nitrogen, and phosphorus accumulation in a highly impacted mangrove wetland. Geophysical Research Letters 41:2475-2480. DOI: 10.1002/2014g1059789.

de Santana CO, Spealman P, Melo VMM, Gresham D, de Jesus TB, Chinalia FA. 2021. Effects of tidal influence on the structure and function of prokaryotic communities in the sediments of a pristine Brazilian mangrove. Biogeosciences 18:2259-2273. DOI: 10.5194/bg-18-2259-2021.

Santos IS, Nolasco M. 2017. Modelagem de Fundo do Estuário do Serinhaém - Ba: Morfologia e Granulometria / Modeling of the bottom of Serinhaém's estuary, BA: Morphology and Granulometry. Caderno de Geografia 27:247. DOI: 10.5752/p.2318-2962.2017v27n49p247.

Schriewer A, Miller WA, Byrne BA, Miller MA, Oates S, Conrad PA, Hardin D, Yang H-H, Chouicha N, Melli A, Jessup D, Dominik C, Wuertz S. 2010. Presence of Bacteroidales as a predictor of pathogens in surface waters of the central California coast. Applied and environmental microbiology 76:58025814. DOI: 10.1128/AEM.00635-10.

Seeley ME, Song B, Passie R, Hale RC. 2020. Microplastics affect sedimentary microbial communities and nitrogen cycling. Nature communications 11:2372. DOI: 10.1038/s41467-020-16235-3.

Spalding M, Kainuma M, Collins L. 2010. World Atlas of Mangroves (version 3.1). A collaborative project of ITTO, ISME, FAO, UNEP-WCMC, UNESCO-MAB, UNU-INWEH and TNC. London (UK): Earthscan, London. URL: http://www.routledge.com/books/details/9781844076574, Data DOI: https://doi.org/10.34892/w2ew-m83

Peer] reviewing PDF | (2021:04:60025:2:1:NEW 29 Aug 2021) 
783

784

785

786

787

788

789

790

791

792

793

794

795

796

797

798

799

800

801

802

803

804

805

806

807

808

809

810

811

812

813

814

815

816

817

818

819

820

Sun S, Jones RB, Fodor AA. 2020. Inference-based accuracy of metagenome prediction tools varies across sample types and functional categories. Microbiome 8:46. DOI: 10.1186/s40168-020-00815-y. Trevathan-Tackett SM, Sherman CDH, Huggett MJ, Campbell AH, Laverock B, Hurtado-McCormick V, Seymour JR, Firl A, Messer LF, Ainsworth TD, Negandhi KL, Daffonchio D, Egan S, Engelen AH, Fusi M, Thomas T, Vann L, Hernandez-Agreda A, Gan HM, Marzinelli EM, Steinberg PD, Hardtke L, Macreadie PI. 2019. A horizon scan of priorities for coastal marine microbiome research. Nature ecology \& evolution 3:1509-1520. DOI: 10.1038/s41559-019-0999-7.

Ullah R, Yasir M, Khan I, Bibi F, Sohrab SS, Al-Ansari A, Al-Abbasi F, Al-Sofyani AA, Daur I, Lee SW, Azhar EI. 2017. Comparative bacterial community analysis in relatively pristine and anthropogenically influenced mangrove ecosystems on the Red Sea. Canadian journal of microbiology 63:649-660. DOI: 10.1139/cjm-2016-0587.

Vavourakis CD, Mehrshad M, Balkema C, van Hall R, Andrei A-Ş, Ghai R, Sorokin DY, Muyzer G. 2019. Metagenomes and metatranscriptomes shed new light on the microbial-mediated sulfur cycle in a Siberian soda lake. BMC biology 17:69. DOI: 10.1186/s12915-019-0688-7.

Wang L, Huang X, Zheng T-L. 2016. Responses of bacterial and archaeal communities to nitrate stimulation after oil pollution in mangrove sediment revealed by Illumina sequencing. Marine pollution bulletin 109:281-289. DOI: 10.1016/j.marpolbul.2016.05.068.

Wang C, Hu R, Strong PJ, Zhuang W, Huang W, Luo Z, Yan Q, He Z, Shu L. 2021. Prevalence of antibiotic resistance genes and bacterial pathogens along the soil-mangrove root continuum. Journal of hazardous materials 408:124985. DOI: 10.1016/j.jhazmat.2020.124985.

Weiss S, Xu ZZ, Peddada S, Amir A, Bittinger K, Gonzalez A, Lozupone C, Zaneveld JR, VázquezBaeza Y, Birmingham A, Hyde ER, Knight R. 2017. Normalization and microbial differential abundance strategies depend upon data characteristics. Microbiome 5:27. DOI: 10.1186/s40168-0170237-y.

Whitman WB, Bowen TL, Boone DR. 2014. The Methanogenic Bacteria. In: Rosenberg E, DeLong EF, Lory S, Stackebrandt E, Thompson F eds. The Prokaryotes: Other Major Lineages of Bacteria and The Archaea. Berlin, Heidelberg: Springer Berlin Heidelberg, 123-163. DOI: 10.1007/978-3-64238954-2_407.

Ye Y, Doak TG. 2009. A parsimony approach to biological pathway reconstruction/inference for genomes and metagenomes. PLoS computational biology 5:e1000465. DOI: 10.1371/journal.pcbi.1000465.

Yun J, Deng Y, Zhang H. 2017. Anthropogenic protection alters the microbiome in intertidal mangrove wetlands in Hainan Island. Applied microbiology and biotechnology 101:6241-6252. DOI: 10.1007/s00253-017-8342-1.

Zhou Z, Meng H, Liu Y, Gu J-D, Li M. 2017. Stratified Bacterial and Archaeal Community in Mangrove and Intertidal Wetland Mudflats Revealed by High Throughput 16S rRNA Gene Sequencing. Frontiers in microbiology 8:2148. DOI: 10.3389/fmicb.2017.02148.

Peer) reviewing PDF | (2021:04:60025:2:1:NEW 29 Aug 2021) 


\section{Figure 1}

Location map of the collection sites of the pristine and impacted mangrove areas.
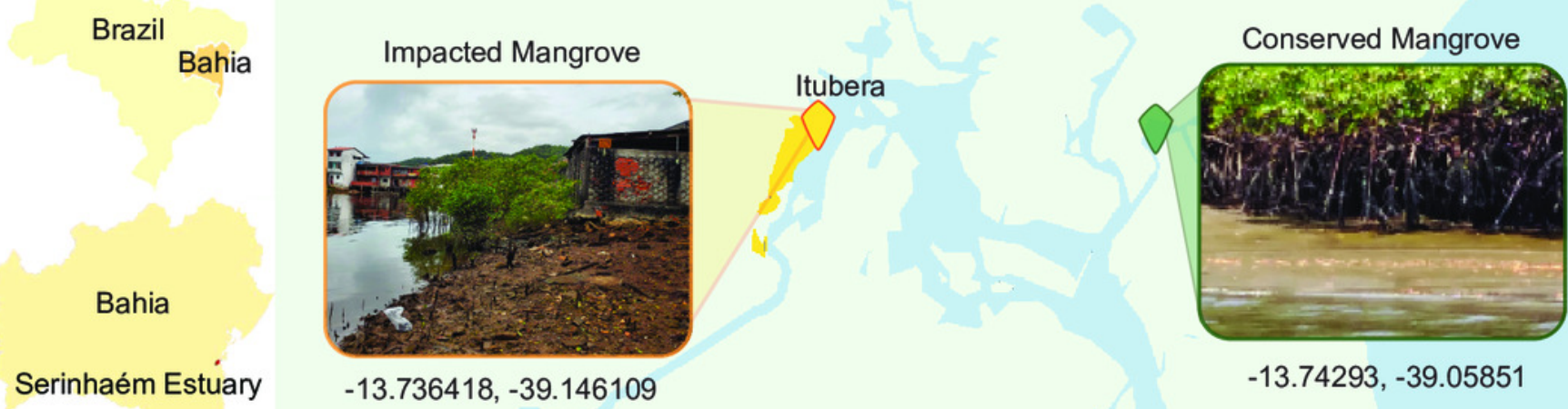

$-13.736418,-39.146109$

$-13.74293,-39.05851$ 
Figure 2

Taxonomic abundances of prokaryotes in each mangrove site.

Summed normalized read abundances from across replicates of prokaryotic groups for phylum and class taxonomic levels at each mangrove site. 


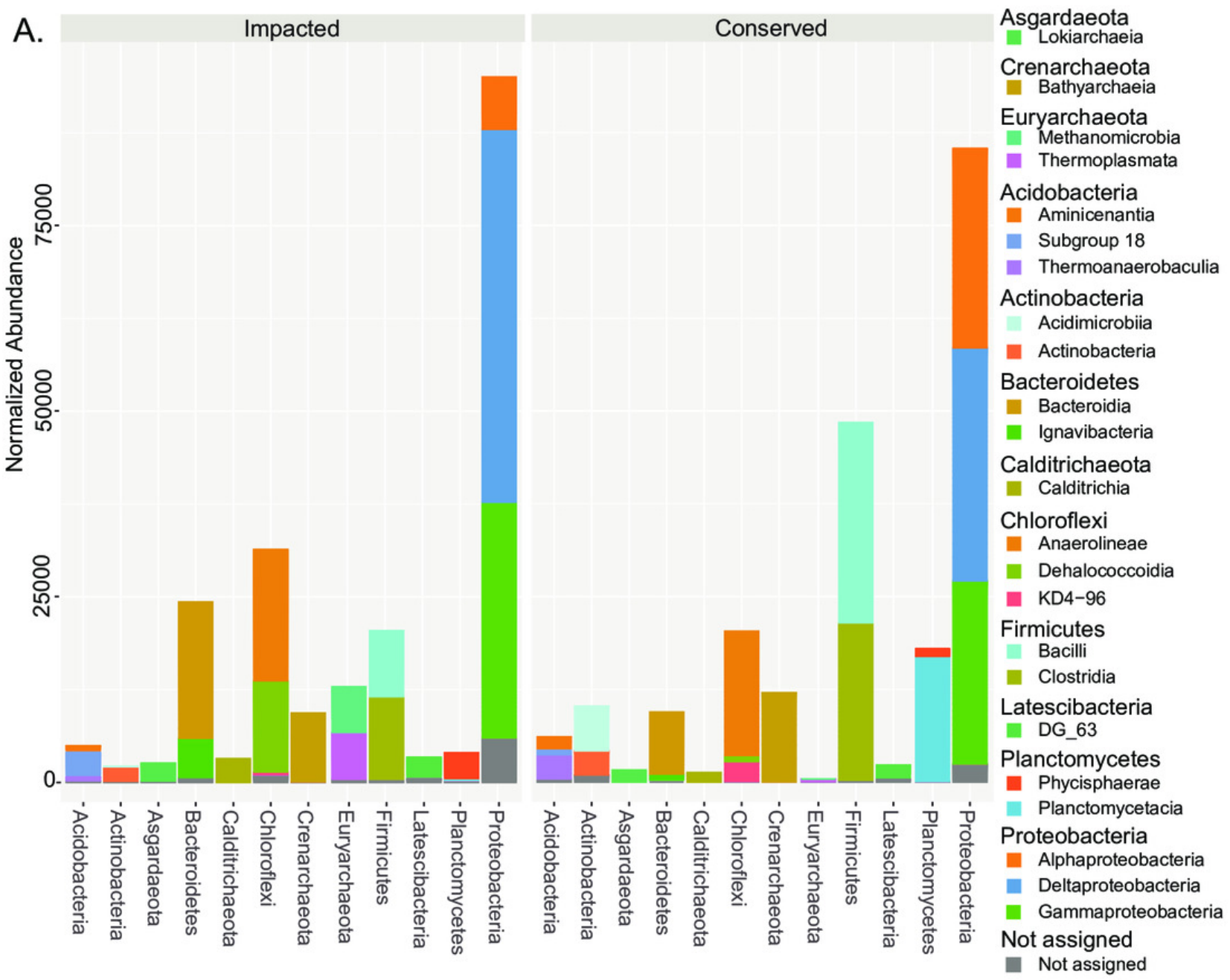




\section{Figure 3}

Prokaryotic diversity and environmental factors interacting to create distinct communities.

Here we show Total ASVs per site (A), alpha-diversity using Shannon's Index (B), and betadiversity using Bray-Curtis (C). A PCoA plot of the sample sites with fitted vectors of environmental variables (D) shows Organic matter, Temperature, and Cu are significantly correlated with the prokaryotic communities, while Dissolved oxygen, $\mathrm{pH}, \mathrm{Ba}$, and Salinity are marginally significant. 
A. Total ASVs

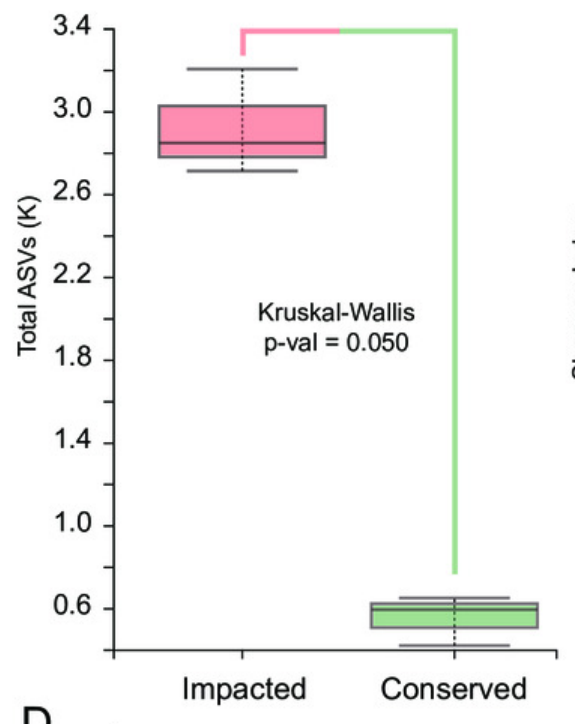

B. Shannon

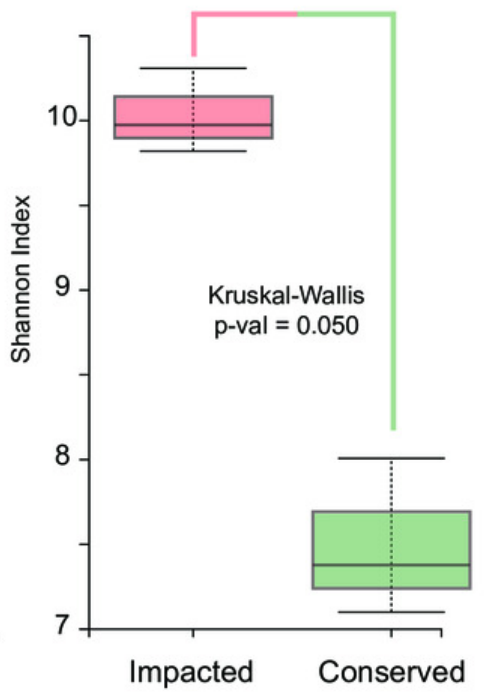

C. Bray-Curtis

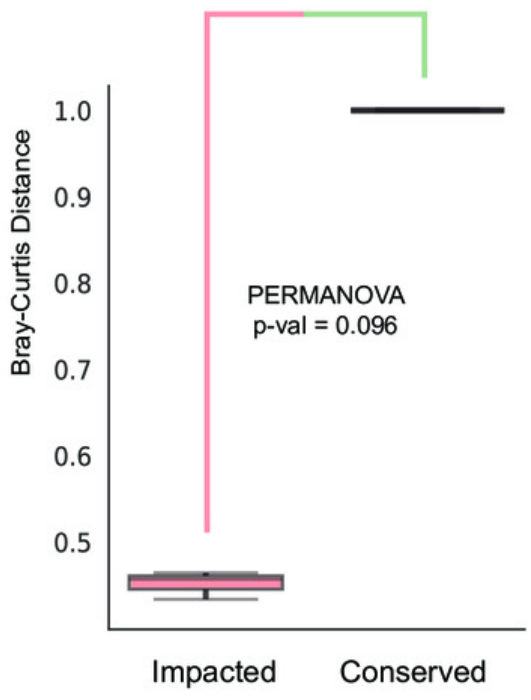

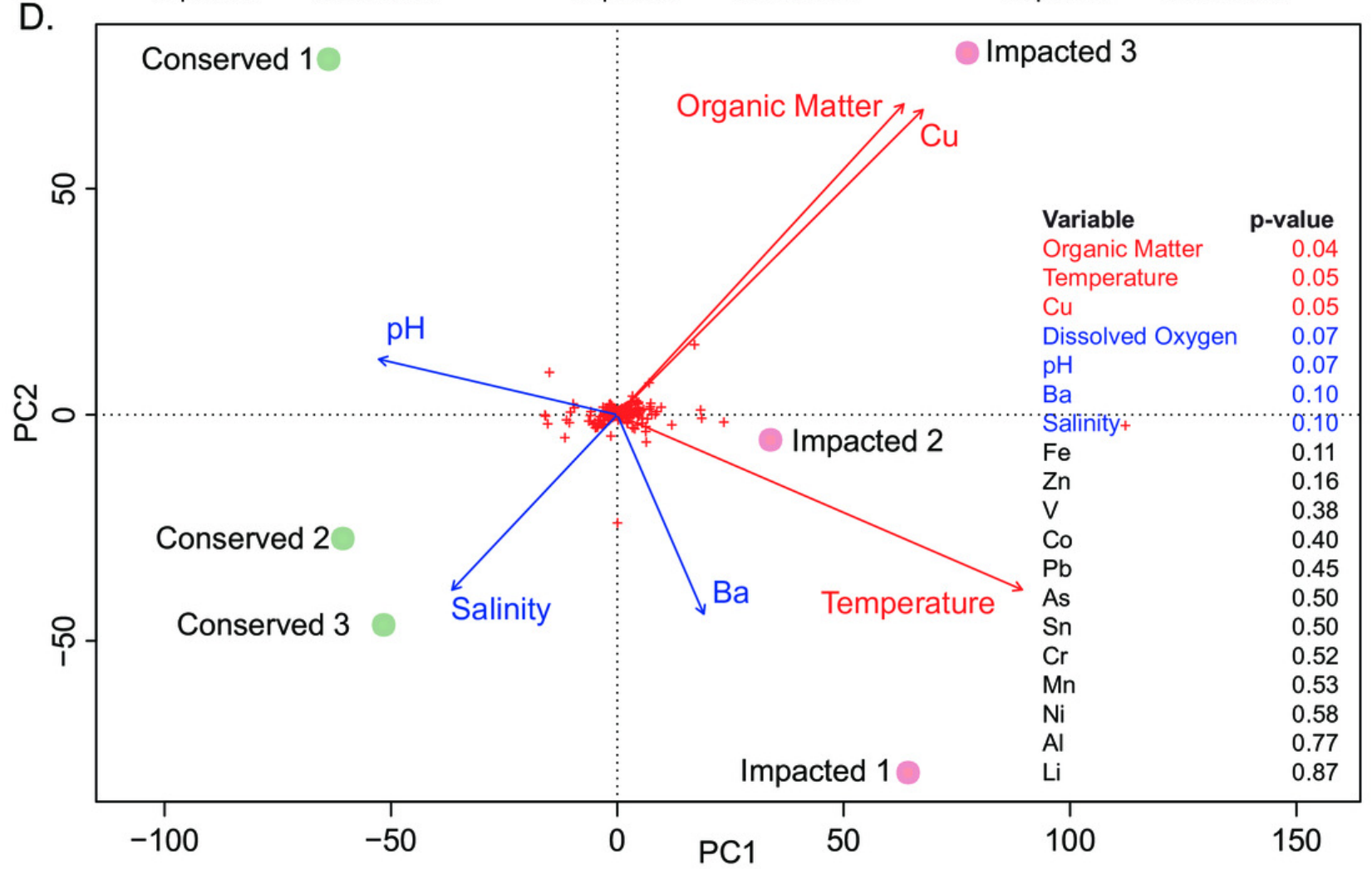




\section{Figure 4}

Taxa with significant differences between impacted and conserved mangrove sites

Prokaryotic families with significant differences in abundances and large effect size

differences ( $>20 \%$ ) between the mangrove sites. Some families show zero abundance in one of the studied areas. 


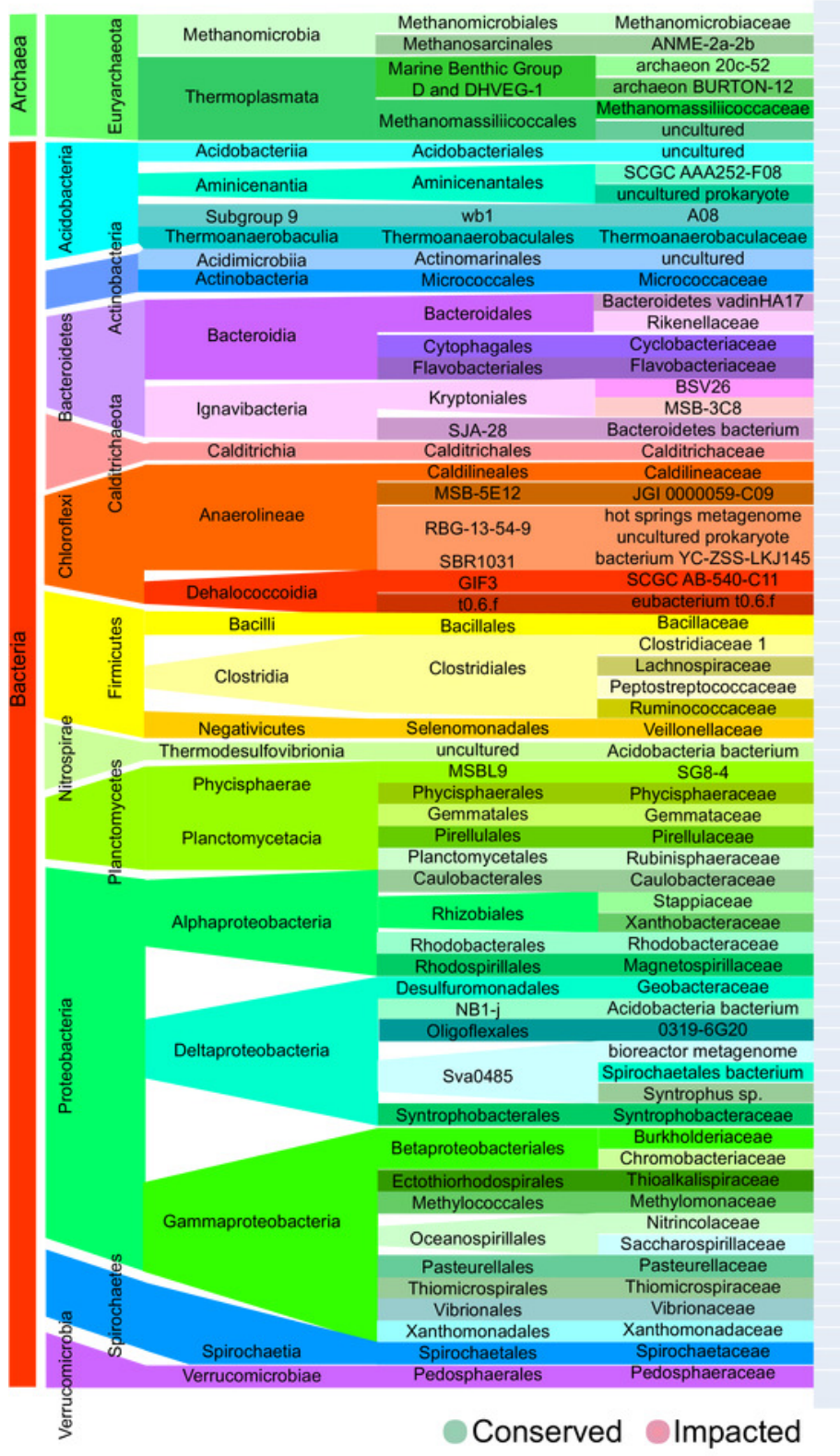

Conserved Impacted
0.5

1.5

2

2.5

3

3.5

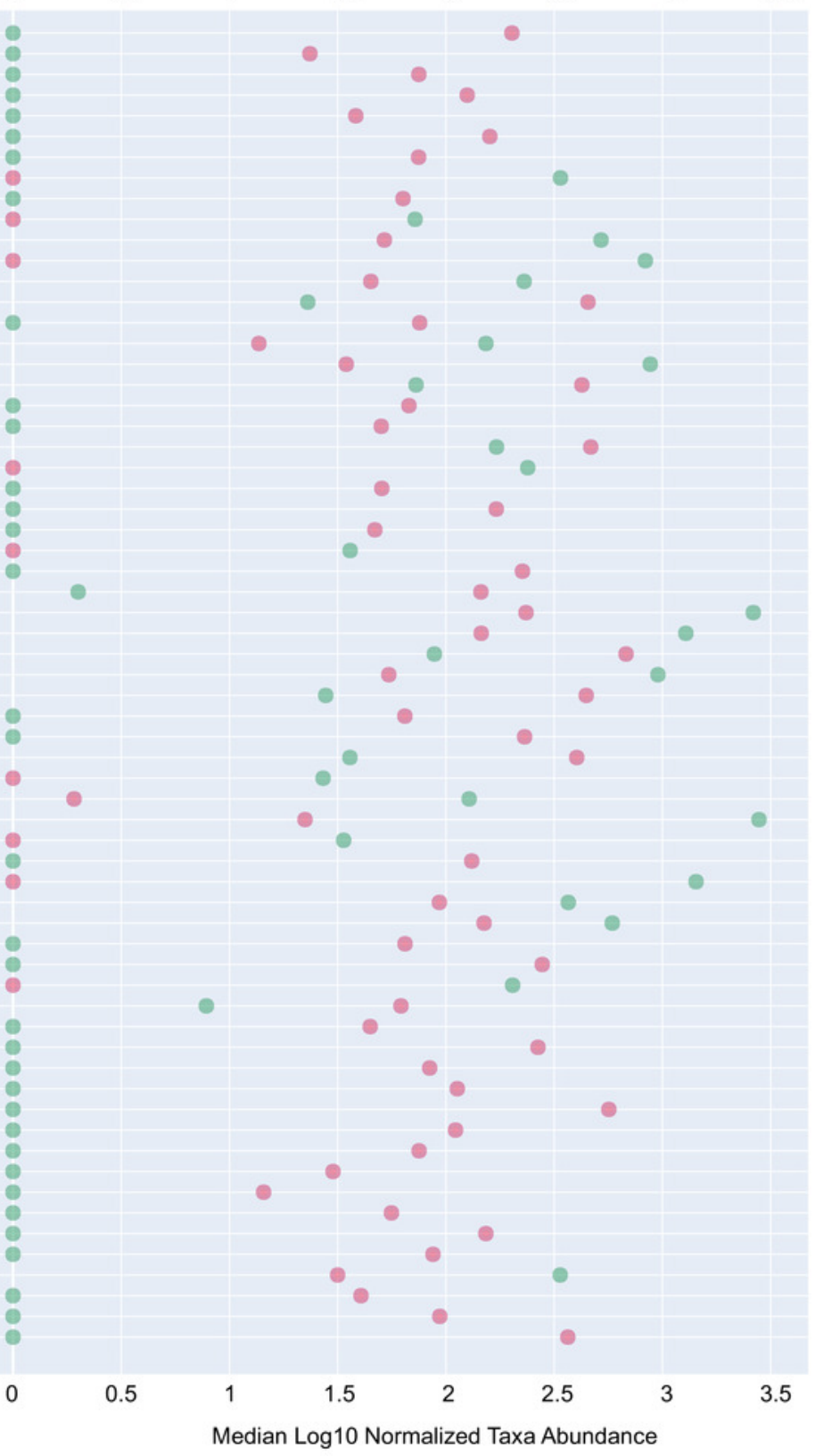




\section{Figure 5}

Carbon metabolism pathways and different abundances between sites.

Abundance heatmaps of carbon metabolic pathways in each site. (A) carbon fixation for photosynthetic organisms. (B) carbon fixation for not photosynthetic organisms. (C) methane metabolism. (D) photosynthesis. 
A.

K18933: mfnA, adc K18277: tmm K17067: mdo K16793: aksE K16792: aksD K16370: pfkB K16305: K1630 K16260: mxaD K16259: mxaL K16258: mxaK K16256: mxaA K16255: mxaG K16254: mxaJ K16179: mtbC K16178: $m$ tbB K16178: $\mathrm{mtbB}$ K16176: $m$ tmB 15634: $\mathrm{pmm}$ K15634. gpmB K15633: gpm K15022: fdhB K14084: mttC K14083: $\mathrm{mttB}$ K14082: mtbA K14081: $m$ taC K14067: mtkA K14029: mdh2, mxal K14028: $\mathrm{mdh} 1$ mxaF K13831: hps-phi K13788: pta K13039: K12234: cofE, fbiB K11780: cofG K11645: fbaB K11645: fbaB K11529: gck, gckA, K11260: fwdG K11212: cofD K10978: aksF K10977: aksA K10714: mtdB K10713: fae K09733: $\mathrm{mfn}$ K09733: mfnB K08692: mtkB K08691: mcl K08265: hdrE K08264: hdrD K08097: comA K08093: hxIA K07821: torY K07812: torZ K07144: mfnE K07072: $\mathrm{mfnF}$ K06914: mfnD K05979: comB K05884: $\mathrm{comC}$ K05884: comC (1) K03532: torC K03422: mcrD K03421: $\mathrm{mcrC}$ K02446: glpX K02203: thrH K01895: ACSS1_2 K01834: PGAM K01689: ENO, eno K01624: FBA, fbaA K01623: ALDO K01595: ppc K01079: serB, PSPH K01070: frmB, ESD K00925: ackA K00918: pfkC K00850: pfkA, PFK K00831: serC, PSAT K00830: AGXT K00672: ftr

K00600: glyA, SHMT K00583: mtrG K00582: mtrF K00580: mtrD K00579: mtrC K00578: $m$ K0577: mtrA (O) K00443: frhG K00440: frhA K00402: mcrG K00401: mcrB K00400: K00400 K00399: mcrA K00319: $\mathrm{mtd}$ K00205: fwdF, fmdF
Methane metabolism
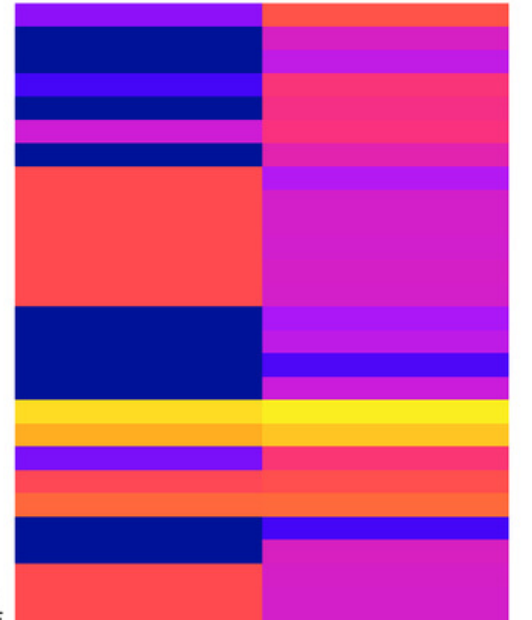

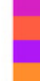
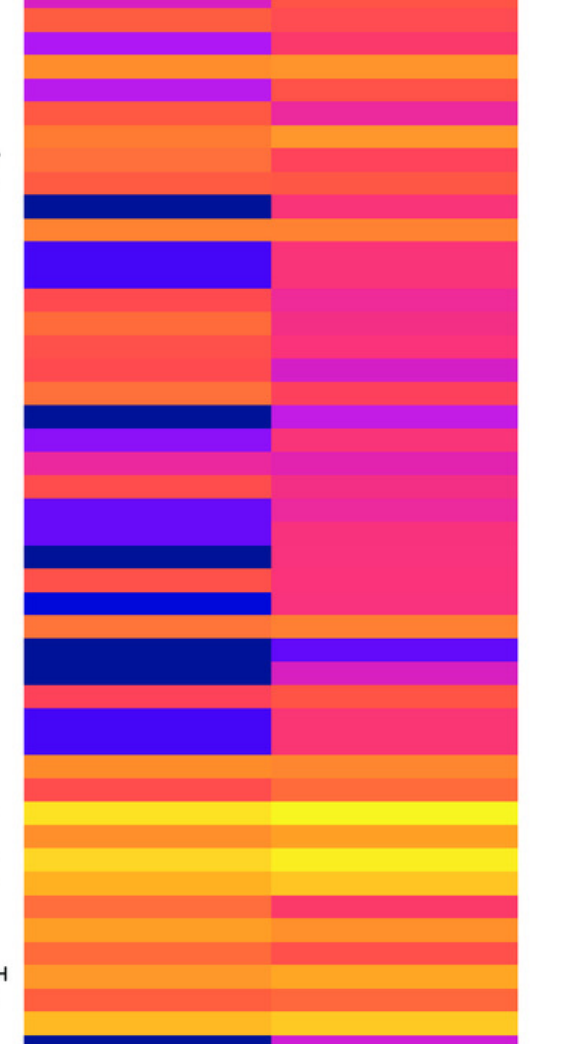
1
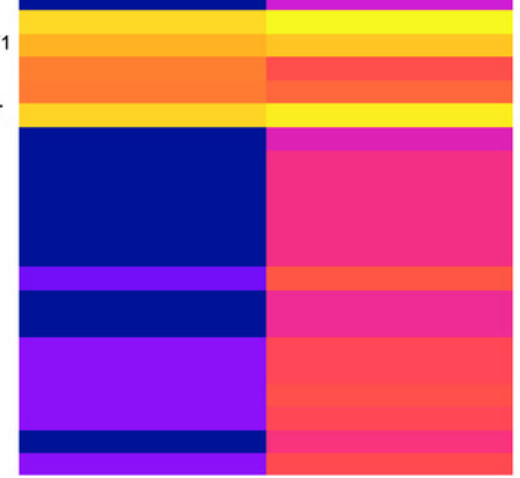

Conserved Impacted

Methane metabolism (cont.)

K00205: fwdF, fmdF K00204: fwdH

K00202: fwdC, fmdC K00201: fwdB, fmdB K00200: fwdA, fmdA K00189: vorG, porG K00127: fdol, fdsG K00126: fdsD K00125: fdhB K00124: fdoH, fdsB K00123: fdoG, fdhF K00122: FDH

K00121: frmA, ADH5

K00058: serA

K00024: mdh

K00018: hprA

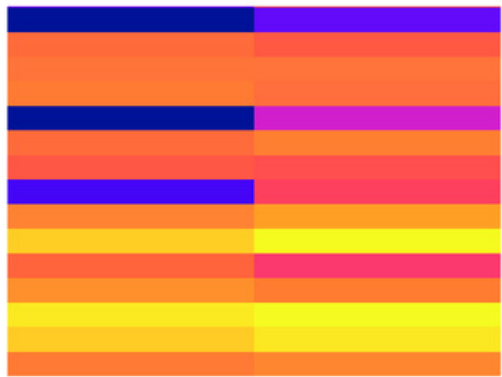

B.

K18210: tfrB K15232: c csA K15231: aclB K15052: K15052 K15052: K15052 K15024: K15024 K15016: K15016 K14534: abfD K14470: mct K14466: K14466 K14449: mch, mcd K13788: pta K09709: meh K08691: mcl K05606: MCEE, epi K02160: accB, bccP K01963: accD

K01962: accA

K01961: accC

K01958: PC, pyc

K01938: fhs

K01903: sucC

K01902: sucD

K01895: ACSS1_2, acs

K01847: MUT

K01682:

K01681: ACO, acnA

K01676: fumA, fumB K01595: ppc

K01491: folD

K01006: ppdK

K00925: ackA

K00626: ACAT, atoB K00297: metF, MTHFR K00242: sdhD, frdD K00241: sdhC, frdC K00240: sdhB, frdB K00239: sdhA, frdA K00189: vorG, K00189: vorG, porG K00024: mdh

\section{Carbon fixation in prokaryotes}

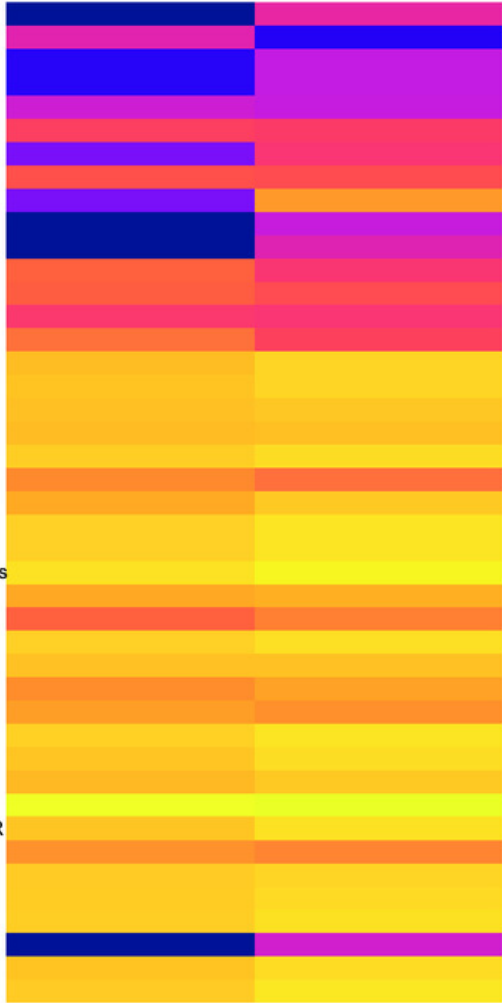

8

C. Carbon fixation in photosynthetic organisms

K11645: fbaB K11532: glpX-SEBP K11214: SHPK K02446: glpX K01808: rрiB K01807: rpiA K01807: rpiA K01803: TPI, tpiA K01624: $F B A$, fba K01624: FBA, fbaA K01623: ALDO K01621: xfp, xpk K01610: pckA K01602: rbcS K01601: rbcL K01595: ppc K01006: ppdK K00927: PGK, pgk K00855: PRK, prkB K00615: tktA, tktB K00134: GAPDH, gapA K00029: maeB K00024: mdh 
Figure 6

Abundances of metabolic pathways of different elements at each site.

Heatmaps of metabolic pathways abundances for nitrogen (A), sulfur (B), pentose phosphate (C), photosynthesis (D). 
A.

K15876: nrfH K15864: nirS

K15579: nrtD, cynD

K15578: nrtC, nasD

K15577: nrtB, nasE

K15576: nrtA, nas

K15371: GDH2

K10535: hao

K03385: nrfA

K02591: nifK

K02588: nifH

K02586: nifD

K02575: NRT, nark

K02567: napA

K02305: norC

K01915: gInA, GLUL

K01673: cynT, can

K01501: E3.5.5

K00459: ncd2, npd

K00376: nosZ

K00374: narl, narV

K00372: nasA

K00366: nirA

K00366: nirA

K00362: nirB

K00284: GLU, gltS

K00284: GLU, gIS

K00266: gitD

K00265: gltB

K00262: gdhA

K00260: gudB, rocG

B.

K17996: hydB K17993: hydA K17230: fcCA K17229: fccB K17227: sOXZ K17226: soxY K17225: soxC K17224: soxB K17223: soxX K17222: soxA K17218: sqr

K17217: mccB K16964: ddhA K16951: asrB K16950: asrA K16937: doxD K15765: tmoF, tbuC K15762: tmoC, tbuB

K15555: ssuB

K15555: ssuB

K15552: tauC

K15551: tauA

K10831: tauB

K10764: metZ

K08354: phsC

K08353: phsB

K08352: phsA, psrA

K07308: dmsC

K07307: dmsB

K07306: dmsA

K06881: nrnA

K05301: sorA

K04091: ssuD

K03119: tauD

K02048: cysP

K02047: cysW

K02046: cysU

K02045: cysA

K01739: metB

K01738: cysK

K01082: cysQ, MET22

K01011: TST, MPST

K00958: sat, met3

K00957: cysD

K00955: cysNC

K00860: cysC

K00651: metA

K00641: metX

K00640: cysE

K00640: cys

K00390: cysH

K00385: asrC

K00381: cysI

K00380: cysJ

K00299: ssuE

K00184: dmsB
Nitrogen metabolism

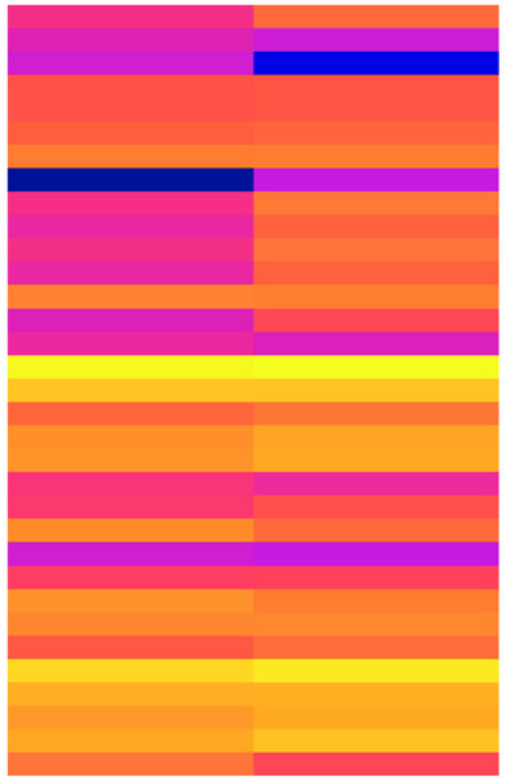

Sulfur metabolism

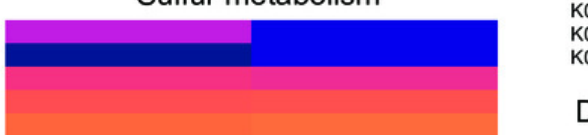

K08906: petJ K08903: psb28 K08902: psb27 K03689: petN K02724: psbZ K02723: psbY K02722: psbX K02719: psbU K02719: psbU K02718: psbT K02717:psbP K02716. psbO K02714: psbM K02713: psbL K02712: psbK K02711: psbJ K02710: psbl K02709: psbH K02708: psbF K02707: psbE K02706: psbD K02705: psbC K02704: psbB K02703: PSA K02703: psbA K02699: psaL K02698: psaK K02697: psaJ K02694: psaF K02693: psaE K02692: psaD K02691: psaC K02690: psaB K02689: psaA K02643: petM K02641: petH K02641: petH K02639: petF K02638: petE K02638: petE K02637: petD K02635: petB K02634: petA K02115: ATPF1C K02114: ATPF1E K02113: ATPF1D K02112: ATPF1B K02111: ATPF1A K02110: ATPFOC K02109: ATPFO K02108: ATPFOA

\section{Pentose phosphate metabolism}

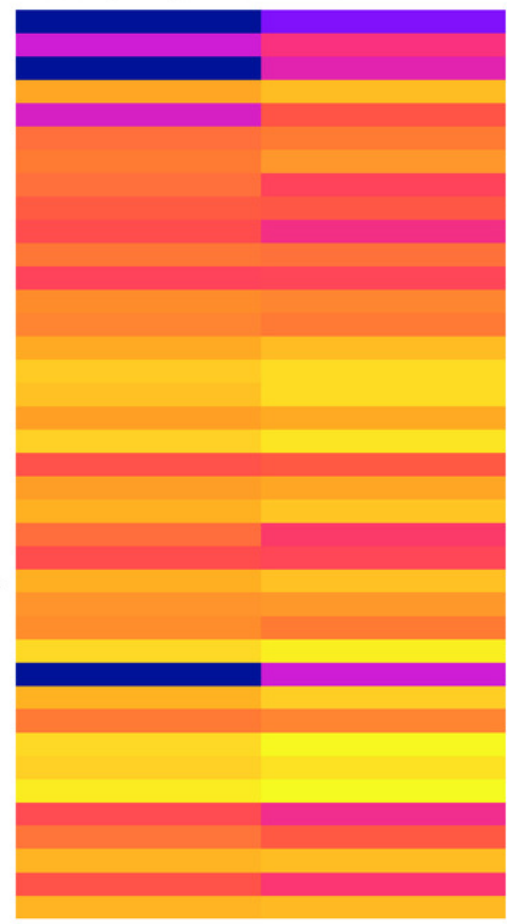

Photosynthesis

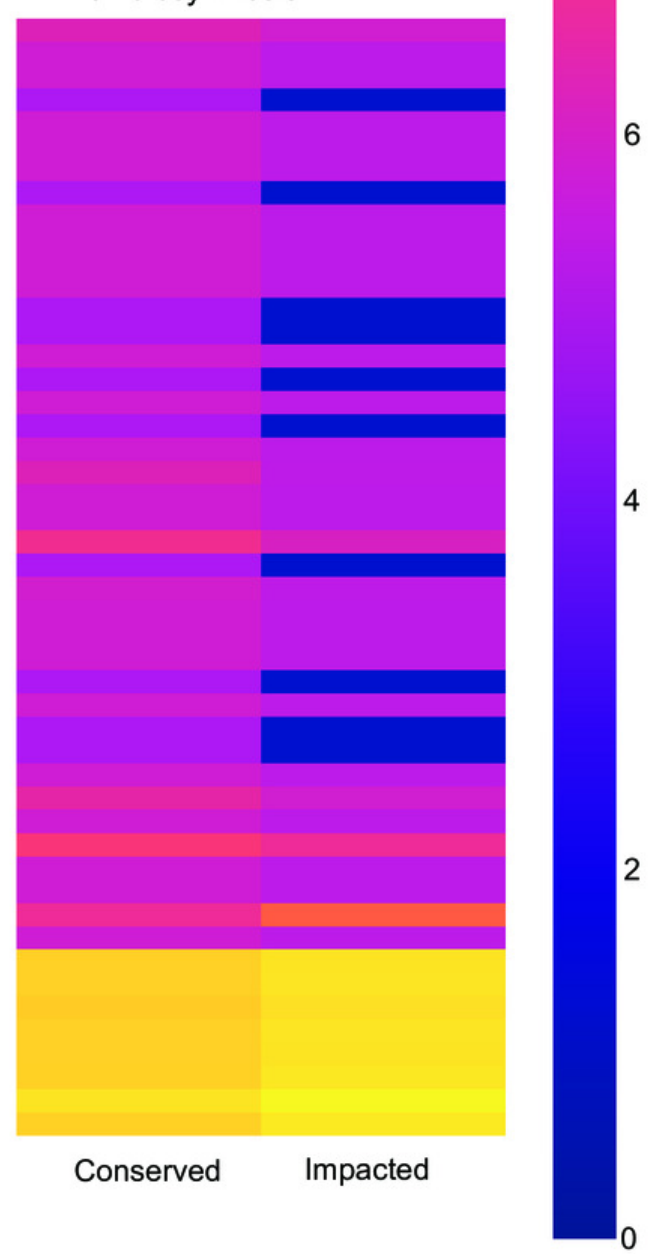


Figure 7

Taxa responsible for the metabolic potentials.

Relative contributions of the prokaryotic families that contribute for $>5 \%$ of the metabolic potentials in at least one site. 
Carbon Fixation in Prokaryotes

Methane

Pentose Phosphate Metabolism

Carbon Fixation in Photosynthetic Organisms

Sulfur Nitrogen Metabolism

Photosynthesis

Impacted

Conserved
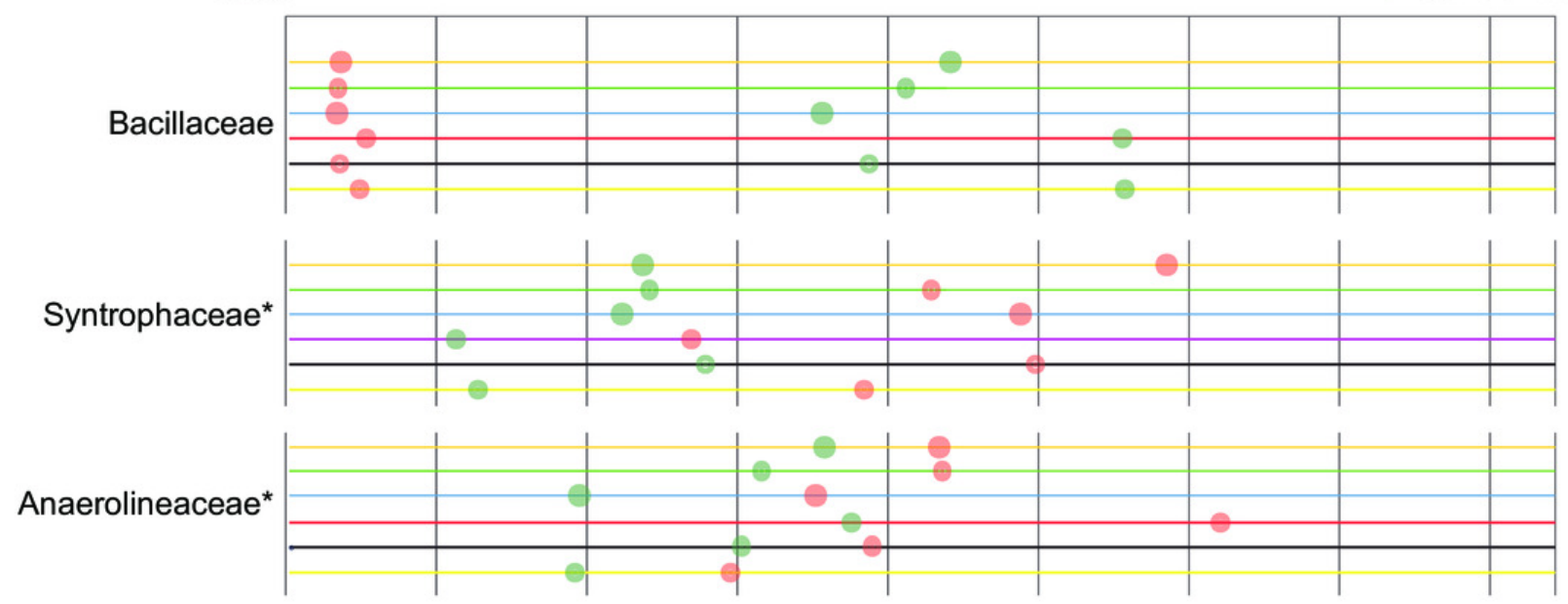

Desulfarculaceae
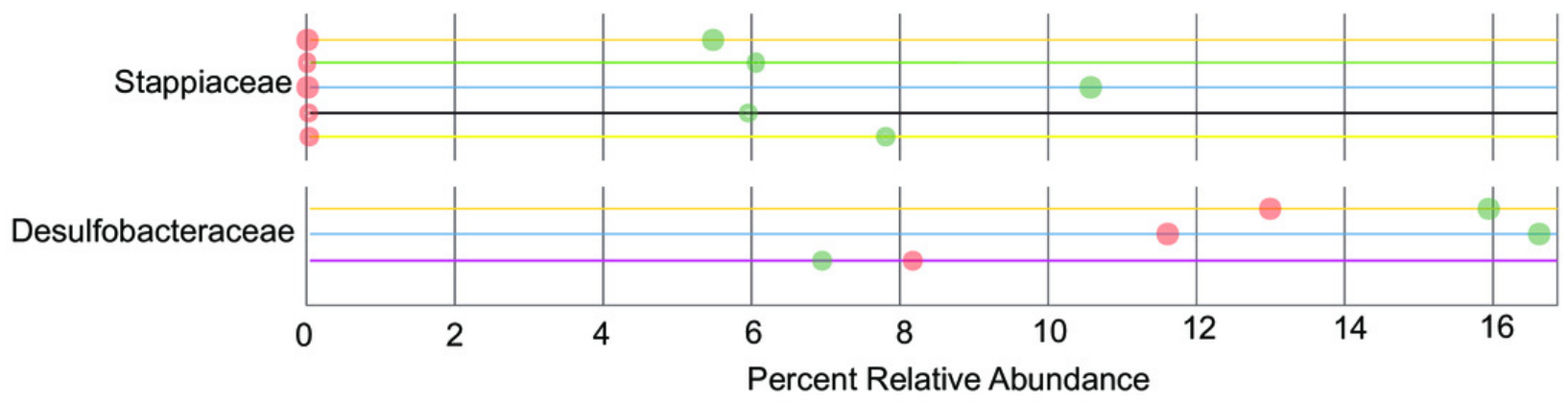

${ }^{*}$ These families had median NSTI values within 1 standard deviation of 0.15 